\title{
Aeroheating Testing and Predictions for Project Orion CEV at Turbulent Conditions
}

\author{
Brian R. Hollis ${ }^{*}$, Karen T. Berger ${ }^{\dagger}$, and Thomas J. Horvath ${ }^{\ddagger}$ \\ NASA Langley Research Center, Hampton, VA, 23681 \\ Joseph J. Coblish ${ }^{\S}$ and Joseph D. Norris ${ }^{* *}$ \\ Arnold Engineering Development Center, White Oak, MD, 20901 \\ Randolph P. Lillard ${ }^{\dagger \dagger}$ and Benjamin S. Kirk ${ }^{\ddagger \ddagger}$ \\ NASA Lyndon B. Johnson Space Center, Houston, TX, 77058
}

\begin{abstract}
An investigation of the aeroheating environment of the Project Orion Crew Exploration Vehicle was performed in the Arnold Engineering Development Center Hypervelocity Wind Tunnel No. 9 Mach 8 and Mach 10 nozzles and in the NASA Langley Research Center 20 Inch Mach 6 Air Tunnel. Heating data were obtained using a thermocouple-instrumented 0.035-scale model (0.1778-m / 7-inch diameter) of the flight vehicle. Runs were performed in the Tunnel 9 Mach 10 nozzle at free stream unit Reynolds numbers of $1 \times 10^{6} / \mathrm{ft}$ to $20 \times 10^{6} / \mathrm{ft}$, in the Tunnel 9 Mach 8 nozzle at free stream unit Reynolds numbers of $8 \times 10^{6} / \mathrm{ft}$ to $48 \times 10^{6} / \mathrm{ft}$, and in the 20-Inch Mach 6 Air Tunnel at free stream unit Reynolds numbers of $1 \times 10^{6} / \mathrm{ft}$ to $7 \times 10^{6} / \mathrm{ft}$. In both facilities, enthalpy levels were low and the test gas $\left(\mathrm{N}_{2}\right.$ in Tunnel 9 and air in the 20-Inch Mach 6) behaved as a perfect-gas. These test conditions produced laminar, transitional and turbulent data in the Tunnel 9 Mach 10 nozzle, transitional and turbulent data in the Tunnel 9 Mach 8 nozzle, and laminar and transitional data in the 20Inch Mach 6 Air Tunnel. Laminar and turbulent predictions were generated for all wind tunnel test conditions and comparisons were performed with the experimental data to help define the accuracy of computational method. In general, it was found that both laminar data and predictions, and turbulent data and predictions, agreed to within less than the estimated $\pm 12 \%$ experimental uncertainty estimate. Laminar heating distributions from all three data sets were shown to correlate well and demonstrated Reynolds numbers independence when expressed in terms of the Stanton number based on adiabatic wallrecovery enthalpy. Transition onset locations on the leeside centerline were determined from the data and correlated in terms of boundary-layer parameters. Finally turbulent heating augmentation ratios were determined for several body-point locations and correlated in terms of the boundary-layer momentum Reynolds number.
\end{abstract}

\section{Nomenclature}

$c_{p} \quad=$ specific heat of test gas $(\mathrm{J} / \mathrm{kg} / \mathrm{K})$

$D=$ maximum vehicle diameter $(\mathrm{m})$

$H_{0} \quad=$ total enthalpy $(\mathrm{J} / \mathrm{kg})$

$H_{300 \mathrm{~K}}=$ cold-wall (at $\left.300 \mathrm{~K}\right)$ enthalpy $(\mathrm{J} / \mathrm{kg})$

$H_{w} \quad=$ enthalpy at measured wall temperature $(\mathrm{J} / \mathrm{kg})$

$M_{\infty} \quad=\quad$ free stream Mach number

$M_{e} \quad=$ boundary-layer edge Mach number

\footnotetext{
* Aerospace Engineer, Aerothermodynamics Branch, Senior AIAA Member

$\dagger$ Aerospace Engineer, Aerothermodynamics Branch, AIAA Member

$\ddagger$ Aerospace Engineer, Aerothermodynamics Branch, AIAA Member

${ }^{\S}$ Lead Project Manager, Senior AIAA Member

${ }^{* *}$ Project Engineer, Aerospace Testing Alliance, AIAA Member

†† Aerospace Engineer, Applied Aerosciences and CFD Branch, Member AIAA

$\$$ Aerospace Engineer, Applied Aerosciences and CFD Branch, Member AIAA
}

1

American Institute of Aeronautics and Astronautics 


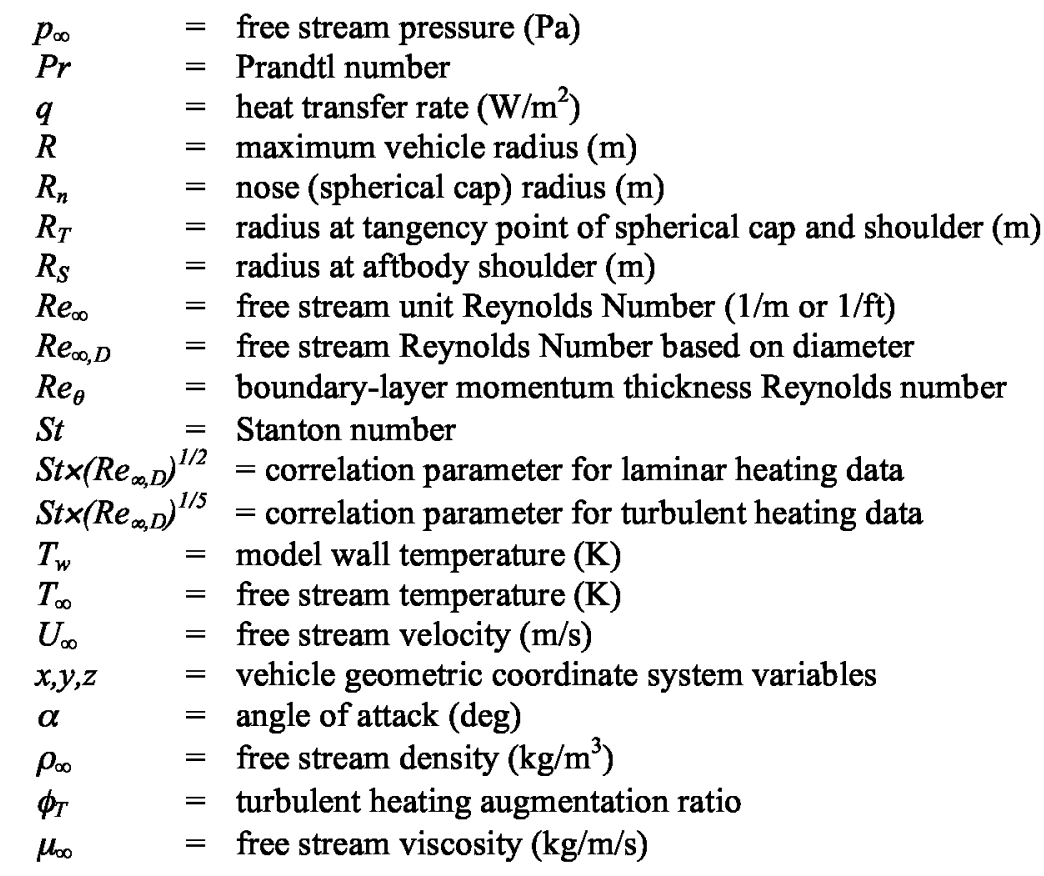

\section{I. $\square$ Background}

The Project Orion Crew Exploration Vehicle (CEV) concept was defined by NASA's Exploration Systems Architecture Study (Ref. 1). This study was conducted in 2005 to define requirements for crew and cargo launch systems to support lunar and Mars exploration programs as well as access to the International Space Station (ISS). Several versions of the Orion CEV are planned that will provide transportation to the ISS, the moon, and Mars.

The Crew Module of the CEV (Figure 1) has a configuration that is externally similar to the Apollo Command Module - a spherical-segment heat shield joined by a small toroidal section to a truncated-cone shaped crew compartment. However, the Orion CEV will be considerably larger than Apollo with a maximum heat shield diameter of $\sim 5 \mathrm{~m}$ (current configuration) vs. $3.912 \mathrm{~m}$ for Apollo. This larger size will allow transport of up to six crew members on International Space Station missions or up to 4 crew members on Lunar missions.

An investigation of the aeroheating environment of the CEV crew module was performed in the Arnold Engineering Development Center (AEDC) Hypervelocity Wind Tunnel No. 9 and the NASA Langley Research Center (LaRC) 20-Inch Mach 6 Air Tunnel. The goals of this study were to determine heating augmentation levels due to turbulent flow on the heat shield (which is the assumed condition for the design of the vehicle) and to obtain high-fidelity heat-transfer measurements on the heat shield in laminar and turbulent flow in order to assess the accuracy of computational fluid dynamics (CFD) predictions.

\section{II. $\square$ Experimental Method}

\section{A. Facility Descriptions}

\section{AEDC Tunnel 9 Description}

The Air Force's Arnold Engineering Development Center Hypervelocity Wind Tunnel No. 9 (Figure 2), located in Silver Spring, Maryland, is a hypersonic, nitrogen-gas, blow-down wind tunnel with interchangeable nozzles that allow for testing at Mach numbers of 7, 8, 10, and 14 over a $0.054 \times 10^{6} / \mathrm{ft}$ to $48.4 \times 10^{6} / \mathrm{ft}\left(0.177 \times 10^{6} / \mathrm{m}\right.$ to 158.8 $\times 10^{6} / \mathrm{m}$ ) unit Reynolds number range (depending on the nozzle). The test section is a $5 \mathrm{ft}(1.52 \mathrm{~m})$ diameter, $12 \mathrm{ft}$ $(3.66 \mathrm{~m})$ long cell that enables testing of large-scale model configurations. Tunnel 9 features a pitch system that can sweep models from $-10 \mathrm{deg}$ to $50 \mathrm{deg}$ at pitch rates up to $80 \mathrm{deg} / \mathrm{sec}$. With the tunnel's $0.2 \mathrm{sec}$ to $15 \mathrm{sec}$ run times, the dynamic pitch capability allows for a large volume of data to be captured over an entire range of pitch angles during a single run. A full description of the facility can be found in Ref. 2

2. LaRC 20-Inch Mach 6 Air Tunnel Description

The NASA Langley Research Center 20-Inch Mach 6 Air Tunnel (Figure 3) is a blow-down facility in which heated, dried, and filtered air is used as the test gas. The tunnel has a two-dimensional contoured nozzle that opens into a $0.521 \mathrm{~m} \times 0.508 \mathrm{~m}(20.5 \mathrm{in}$. $20.0 \mathrm{in}$.) test section. The tunnel is equipped with a bottom-mounted injection 
system that can transfer a model from the sheltered model box to the tunnel centerline in less than 0.5 sec. Run times of up to 15 minutes are possible in this facility, although for the current aeroheating study, run times of only a few seconds were required. The nominal reservoir conditions of this facility produce perfect-gas free-stream flows with Mach numbers between 5.8 and 6.1 and unit Reynolds numbers of $0.5 \times 10^{6} / \mathrm{ft}$ to $7.3 \times 10^{6} / \mathrm{ft}\left(1.64 \times 10^{6} / \mathrm{m}\right.$ to $\left.23.3 \times 10^{6} / \mathrm{m}\right)$. A more detailed description of this facility is presented in Ref. 3 .

\section{B. Test Parametrics}

1. AEDC Tunnel 9 Test Parametrics

A total of 31 runs were performed in this AEDC Tunnel 9 test. Free-stream conditions are listed in the run matrix in Table 1. The majority of runs (23) were performed in the Mach 10 nozzle at nominal free-stream unit Reynolds numbers of $2,5,9,15$ and $20 \times 10^{6} / \mathrm{ft}$, while the rest of the runs were performed in the Mach 8 nozzle at nominal free-stream unit Reynolds numbers of $8,17,31$, and $48 \times 10^{6} / \mathrm{ft}$. During several of the runs, interchangeable insert pieces with discrete and distributed roughness elements of various sizes were employed to promote boundarylayer transition. During the planning stages of this test, the trim angle-of-attack of the CEV in flight was expected to be 28-deg (152-deg in the formal CEV coordinate system, which is rotated 180-deg from that of the wind tunnel model coordinate system), but it has since changed to $\sim 20$-deg. To allow for design changes or deviations during flight that affect the nominal pitch attitude, pitch sweeps of 20-deg to 32-deg and static 28-deg runs were performed in the Mach 10 nozzle and pitch sweeps of 24-deg to 32-deg (the smaller increments were due to shorter test times) were made in the Mach 8 nozzle. A few runs were also performed at 0-deg angle-of-attack as a symmetry check and with pitch sweeps of 16-deg to 30-deg to obtain lower angle-of-attack data.

2. NASA LaRC 20-Inch Mach 6 Air Tunnel Test 6931 Parametrics

A total of 68 runs were conducted in LaRC 20-Inch Mach 6 Air Tunnel Test 6931 and additional testing devoted to transition onset studies was subsequently conducted as detailed in Ref. 4. The run matrix for this test is presented in Table 2. The first 32 runs were performed at static angles-of-attack from 20-deg to 32-deg. Eleven runs were then conducted with continuous pitch-sweep of the model from 16-deg to 32-deg for comparison with the static angle-of-attack data to permit evaluation of this mode of operation. Finally, 25 runs were performed in continuous pitch-sweep mode with discrete boundary-layer trips of various sizes with the intent of producing turbulent flow.

\section{Wind Tunnel Model Design}

A 0.03556-scale model of the CEV crew module (based on an assumed $5.00 \mathrm{~m}$ full-scale vehicle when the model was designed) was built for this test. A drawing of the model is given in Figure 4 (note that the current configuration has advanced beyond that shown) and it is shown installed in Tunnel 9 in Figure 5. The model was fabricated from 15-5 precipitation-hardened stainless steel with an $\mathrm{H} 1100$ heat treatment. The model's maximum diameter of $17.78 \mathrm{~cm}(7.00$-in) was chosen for consistency with previous CEV tests (Refs. 5,6) and to allow testing of this model in NASA Langley Research Center 20-Inch Mach 6 Air Tunnel. The model was designed to permit substitution of a removable insert piece on the lower half of the forebody heat-shield. Inserts with varying forms of distributed and discrete roughness elements were fabricated to allow for investigation of roughness effects on transition and turbulent heating. In the current program, a very limited study of trip effects was conducted in Tunnel 9 using inserts with discrete roughness elements of 0.007 -in. nominal height and distributed roughness elements of 0.001-in., 0.007-in., and 0.012-in. nominal heights. In the LaRC 20-Inch Mach 6 Air Tunnel tests, trip-effect studies were performed using discrete squares of kapton tape with heights of 0.0045 -in., 0.0065 -in. and 0.115 -in., as per the method discussed in Ref. 7.

The model was instrumented with 101 MedTherm Type-E (chromel-constantan) coaxial thermocouples. These gages were press-fit through holes drilled into the model and then hand-worked to conform to the model surface and to form the required electrical junctions between the chromel and constantan elements of the thermocouples. The voltage output of a thermocouple is related to temperature through National Institute of Standards and Technology (NIST) calibration standards (Ref. 8). Temperature-time history data from the thermocouple measurements are then processed through conduction analysis to determine heat-transfer rate time-histories.

There were 82 gages located on the forebody heat-shield portion of the model and the remaining 19 gages were located on the aftbody crew compartment. Gages on the heat shield were arrayed vertically along the centerline (pitch-plane) of the model and horizontally across the leeside (top) of the model where the highest turbulent augmentation occurs. As the data set produced from these two tests is very large, only the data from the 43 gages located along the centerline will be discussed in detail herein.

\section{Data Acquisition and Reduction}


Thermocouple voltage data from AEDC Tunnel 9 were acquired at a frequency of $500 \mathrm{~Hz}$ while data from the LaRC 20-Inch Mach 6 Air Tunnel were acquired at $40 \mathrm{~Hz}$. The difference in data acquisition rates is a function of the different run times in these two tunnels - on the order of 1 second in Tunnel 9 vs. several seconds in the 20-Inch Mach 6 Air Tunnel. In both facilities, the data acquisition rates were sufficient for time-averaging of the quasisteady flow-fields generated by continuous pitch-sweep testing.

Voltage data were converted to temperatures via the NIST standard calibration formula for Type-E thermocouples. These data were then used to compute heat-transfer rates through a one-dimensional finitedifference numerical method. Descriptions of the software packages QCALC and 1DHEAT used by AEDC and NASA LaRC to perform this analysis can be found in Refs. 9 - 11. As a check on the data reduction process, the test data were reduced using both LaRC and AEDC software tools. Results from the two software tools were essentially identical.

As discussed previously in Refs. 12-13 for a similar test program, comparisons of experimental data with the computational results indicated substantial uncertainties in the thermal properties (i.e. conductivity and specific heat) of the model and thermocouple materials. This uncertainty had a first-order effect on the heating distributions determined from the data and considerable testing was conducted to verify the properties employed.

\section{E. Heating Parameters}

Although the conduction analysis determines dimensional heat-flux values at the model surface, this is not the ideal parameter with which to report the experimental data. Over the course of a run the heat-flux experienced by the model varies, mostly due to increasing temperatures on the model surface, but also slightly due to variations in free stream conditions. In the AEDC Tunne1 9, surface temperature increases of up to $150 \mathrm{~K}$ were measured (at the highest Mach 8 Reynolds number condition) while free-stream conditions varied up to a maximum of $\sim 5 \%$. In the LaRC 20-Inch Mach 6 Air Tunnel, surface temperature increases of up to $30 \mathrm{~K}$ were measured, while free stream conditions varied by $\sim 1 \%$ over the course of a run. Because these factors caused the dimensional heat-transfer rates to vary, a more appropriate parameter with which to report the data is the Stanton number, which remains nominally nearly a constant for given conditions (e.g. Ref. 14). Data from runs at various Reynolds numbers (for a given enthalpy) can then be correlated through multiplication by the square root of the free-stream Reynolds number for laminar conditions, as in Eq. (1), or by free-stream Reynolds number to the $1 / 5^{\text {th }}$ power for turbulent cases, as in Eq. (2). Results herein will be presented in terms of these parameters. In order to account for noise and transient fluctuations, the reported values represent averages over either the whole course of the run for static angle-of-attack cases or over 1-deg angle-of-attack increments for continuous pitch-sweep cases.

(1) $S t \times\left(\operatorname{Re}_{\infty, D}\right)^{1 / 2}=\frac{q}{\rho_{\infty} U_{\infty}\left(H_{0}-H_{w}\right)}\left(\frac{\rho_{\infty} U_{\infty} D}{\mu_{\infty}}\right)^{1 / 2}$, laminar correlation parameter

(2) $S t \times\left(\operatorname{Re}_{\infty, D}\right)^{1 / 5}=\frac{q}{\rho_{\infty} U_{\infty}\left(H_{0}-H_{w}\right)}\left(\frac{\rho_{\infty} U_{\infty} D}{\mu_{\infty}}\right)^{1 / 5}$, turbulent correlation parameter

where

(3) $\left(H_{0}-H_{w}\right)=\left(c_{p} T_{\infty}+\frac{U_{\infty}^{2}}{2}\right)-c_{p} T_{w}$

To illustrate the differences between heat-flux and Stanton number, a sample set of Tunnel 9 flow conditions is shown in Figure 6 along with the computed values for a forebody gage in terms of each parameter. The Stanton number can be time-averaged to eliminate fluctuation in the data whereas the heat-flux cannot. Another benefit of the Stanton number definition is that the temperature dependence is removed and thus a constant wall temperature may be specified in computational fluid dynamics solutions rather than a variable temperature distribution over the entire body.

Reynolds number dependencies are also removed when using Eqs. (1) or (2). As shown in Figure 7, $S t x\left(\operatorname{Re}_{\infty, D}\right)^{0.5}$ can be used to approximately correlate laminar heat-flux distributions over the range of test conditions. Transitional/turbulent data can clearly be identified when the values diverge from the lower Reynolds number data, which are nearly constant. Similarly, $S t \times\left(R e_{\infty, D}\right)^{0.2}$ can be used to correlate turbulent data, as in Figure 8 . 
It should be noted that the definition of the Stanton number used herein is based on free stream conditions and total enthalpy. Stanton numbers are also sometimes defined in terms of edge conditions and/or in terms of an adiabatic wall-recovery enthalpy. These definitions are not equivalent. The definitions used in Eqs. (1) - (3) are the simplest to use for data reduction because they do not require a flow-field computation to generate the edge conditions or the use of a recovery factor that has both flow-field and geometric dependencies.

\section{F. Experimental Uncertainty}

The greatest source of uncertainty $(\sim 10-20 \%)$ in the experimental methodology was found to be in the material thermal properties used in the conduction analysis by which heating rates were determined from the temperaturetime history data. Without a thorough statistical investigation of the material thermal properties, which is beyond the scope of this study, the overall uncertainty cannot be better defined. However, a variety of comparisons with calibration standards and predicted heating rates (as detailed in Refs. 12 - 13) suggest that the thermal properties used in this study (as given in Ref. 12) are reasonably accurate. In addition to uncertainties resulting from material properties, there were also uncertainties introduced due to variations in free stream conditions, model angle of attack, instrumentation precision, etc. AEDC quotes a uncertainty of $\pm 6 \%$ for these factors and this estimate is assumed to be conservative for testing in the LaRC Mach 6 facility as the variation in free-stream conditions is lower. An overall experimental uncertainty of $\pm 12 \%$ can then be estimated from the root-mean-square value of a low-end material properties uncertainty estimate of $\pm 10 \%$ with the AEDC-quoted $\pm 6 \%$ for other factors.

\section{III. $\square$ Computational Method}

Flow field computations at the wind tunnel test conditions were performed using the LAURA code (Refs. 15 16). The LAURA (Langley Aerothermodynamic Upwind Relaxation Algorithm) code is a three-dimensional, finitevolume solver that includes perfect-gas, equilibrium, and non-equilibrium chemistry models. The code can be used to solve the inviscid Euler, viscous thin-layer Navier-Stokes, or full Navier-Stokes equations. In the current study, the thin-layer model was employed; it was concluded in previous studies (Ref. 17) from computations on a similar blunt body that this model provided accurate results for attached forebody flows. Time integration to steady-state in LAURA is accomplished through a point-relaxation scheme. Roe-averaging (Ref. 18) with Harten's entropy fix (Ref. 19) and Yee's Symmetric Total Variation Diminishing limiter (Ref. 20) is used for inviscid fluxes, and a second-order scheme is employed for viscous fluxes. In this study, a perfect-gas model was used for the AEDC and LaRC tunnel conditions with the appropriate gas parameters for either pure $\mathrm{N}_{2}$ (AEDC Tunnel 9) or air (LaRC 20Inch Mach 6 Air Tunnel).

For the AEDC CFD cases, free-stream conditions were extracted from the tunnel conditions data set for that run for the time when the specified angle-of-attack was reached since conditions varied over the course of a run. For the wall boundary condition, a uniform temperature was specified over the entire body equal to that recorded at the nose of the model at the specified time during the run. For the LaRC 20-Inch Mach 6 Air cases, free-stream conditions did not vary significantly over the length of the run, so the nominal conditions were used. The wall temperature boundary condition was specified in the same manner as for the AEDC CFD cases.

Structured, finite-volume, multiple-block forebody grids with a singularity-free nose were employed for the computations. Grid adaptation was performed (as per the method detailed in reference 16) to align the grid with the bow shock and to produce nominal wall-cell Reynolds numbers on the order of 1 .

Laminar computations were performed for all AEDC and LaRC tunnel cases. Turbulent computations were performed for higher Reynolds number cases using the algebraic Cebeci-Smith turbulence model (the algebraic Baldwin-Lomax model was used for a few selected AEDC cases and found to produce only slightly different results at these perfect-gas conditions). While it is recognized that more sophisticated turbulence models exist, different models can produce very different results (e.g. reference 21) and the validation status of any turbulence model for hypersonic flow over a given vehicle type is debatable. Algebraic models are fast and stable, and as will be shown subsequently, their accuracy for attached forebody flows is generally as good as that of the laminar predictions at least for the conditions under consideration.

\section{Results and Analysis}

\section{A. Data Overview}

The data sets obtained in these tests, which comprise data from over 100 thermocouples from almost 100 wind tunnel runs, during which data were obtained at multiple angles of attack, is too large to comprehensively present and discuss herein. Therefore, the focus of this report will be on the heat-shield centerline data and a limited 
selection of the crew module centerline data. The remainder of the data have been supplied to the CEV program and will be documented later in formal reports. The centerline data (i.e. $x-z$ symmetry plane) to be shown in subsequent sections is the most important data to the CEV project since the centerline heating is the highest on the body.

As noted previously, data were obtained in the two facilities at angles-of-attack varying from 16-deg to 32-deg, although not all angles were covered at all operating conditions. At the time these tests were performed, the trim angle of the flight vehicle was expected to be 28-deg and the test range was centered on that angle. As design work on the CEV progressed, the expected trim angle shifted toward $~ 20$-deg. In order to focus on the angles-of-attack of most interest to the CEV program, only the data for $\alpha=20-\mathrm{deg}, 24-\mathrm{deg}$ and 28-deg will be discussed.

\section{B. Off-centerline data}

To provide some illustration of heating levels over the entire body, heating levels at each of the heat-shield thermocouples are shown for sample cases for the LaRC 20-Inch Mach 6 Air Tunnel and the two AEDC Tunnel 9 nozzles in Figure 9 - Figure 11. The cases shown are for the highest Reynolds number cases in each facility and thus are of most interest in showing the extent of off-centerline turbulent heating. At the LaRC Mach 6 condition, the heating levels corresponded to laminar or barely transitional flow over the whole body. At the AEDC Mach 10 condition the data was transitional or turbulent over most of the leeside of the heat-shield (the top half of the image) and at the AEDC Mach 8 condition, the data were turbulent everywhere on the heat-shield.

\section{Tripped Boundary-Layer Data}

Tripped boundary-layer data will not be discussed in detail herein. As noted previously, the wind tunnel model was designed with a replaceable section near the nose into which inserts with various trip height and patterns could be substituted. However, it was found that at the AEDC Tunnel 9 operating conditions, fully-developed turbulent flow could be produced without use of the trips. Therefore, preliminary plans for an extensive investigation of trip parameters in this facility were curtailed. In the LaRC 20-Inch Mach 6 Air Tunnel, 25 runs were conducted with discrete trips placed on the centerline between the geometric nose and the stagnation point. The purpose of these runs was to determine whether or not the use of boundary-layer trips could produce fully-developed turbulent flow at the lower Reynolds number operating conditions of the Mach 6 tunnel on the CEV configuration. The trips definitely caused boundary-layer transition, but the data did not conclusively support the production of fullydeveloped turbulent flow, which was the goal of the trip-study. Therefore, the trip data will not be presented herein. However, these data, as well as subsequent test data obtained with a wider range of trip parameters are discussed from the perspective of boundary-layer transition criteria in Ref. 4.

\section{Centerline Data and Comparisons with Predictions}

A sampling of the heat-shield centerline data from each facility will be discussed in this section. These data are plotted in Figure 12 for the LaRC 20-Inch Mach 6 Air Tunnel, Figure 13 for the AEDC Tunnel 9 Mach 10 nozzle, and Figure 14 for the AEDC Tunnel 9 Mach 8 nozzle. Each figure includes data, where available, for $\alpha=20$-deg, 24-deg and 28-deg at each Reynolds number operating condition of the respective facility. There are two plots shown side-by-side for each case. The left-hand plot is a comparison of the predicted and measured values of the laminar heating correlation parameter $S t \times\left(R e_{\infty, \mathrm{D}}\right)^{1 / 2}$. In these comparison plots between experimental and computational values, error-bars are shown on the data that correspond to the $\pm 12 \%$ experimental uncertainty discussed previously. The comparisons shown in these figures have been used to help define uncertainties for both laminar and turbulent convective heating computational methods used to predict flight environments. The righthand plots show the experimental heating data for each condition along with the predicted laminar values of two boundary-layer parameters, $R e_{\theta}$ and $R e_{\theta} / M_{\mathrm{e}}$, that are commonly used in analysis of smooth-body boundary-layer transition data. The boundary-layer parameters are shown at this point for convenience of presentation and will be used in a subsequent section to correlate leeside centerline transition onset data.

In the LaRC Mach 6 tunnel (Figure 12), the laminar predictions generally fell within the experimental uncertainty of the data. The exceptions were on the leeside of the heat-shield $(z / R>0.5)$ at the highest Reynolds number condition $\left(R e_{\infty}=7.4 \times 10^{6} / \mathrm{ft}\right)$ where the boundary-layer appeared to become transitional, and in the stagnation region $(z / R=-0.7$ to -0.8 depending on angle-of-attack). The augmentation of the experimental heating data in the stagnation region above surrounding levels has been observed previously in other facilities and with different configurations (Refs. 12, 22-24). Therefore it is thought to be a real, non-laminar or unsteady flow phenomenon, as opposed to an artifact of a particular test facility, instrumentation type, or vehicle configuration.

At the AEDC Mach 10 conditions (Figure 13), the data indicated laminar behavior at $R e_{\infty}=2.0 \times 10^{6} / \mathrm{ft}$ and $R e_{\infty}=$ $4.8 \times 10^{6} / \mathrm{ft}$, the beginning of leeside transition at $R e_{\infty}=8.9 \times 10^{6} / \mathrm{ft}$, and fully-developed turbulent flow over at least 
part of the leeside for $R e_{\infty}=14.6 \times 10^{6} / \mathrm{ft}$ and $R e_{\infty}=19.6 \times 10^{6} / \mathrm{ft}$. Regions of laminar data and regions of turbulent data each matched the respective laminar or turbulent predictions to within the experimental uncertainty for all conditions. Transitional data (generally between the stagnation point and geometric nose) fell between predicted laminar and turbulent levels. In the stagnation region, an augmentation of heating levels above both the surrounding region and the predicted laminar levels was again observed.

The highest test Reynolds numbers were produced at the AEDC Mach 8 conditions (Figure 14) and all data were at least transitional over most of the body for all conditions. At the highest Reynolds number $\left(R e_{\infty}=47.9 \times 10^{6} / \mathrm{ft}\right)$ the data appeared to be turbulent over the entire heat shield. Both laminar and fully-turbulent predictions were generated for these conditions. For all but the lowest (transitional) Reynolds number, the turbulent predictions for the leeside were within the experimental uncertainty. On the windside of the body, the turbulent predictions were also similar to the experimental data. However, the sparseness of the data between the stagnation region and windside shoulder ( 3 or 4 gages depending on angle-of-attack) and the large heating gradient there made it difficult to assess the accuracy of the comparisons.

From these figures and analyses, the following conclusions can be made: 1) Transition occurred first on the leeside of the heat-shield and only occurred on the windside at much higher Reynolds numbers; 2) The accuracy of the predictions was generally as good as or better than the experimental uncertainty for fully-laminar or fullyturbulent conditions. For transitional cases, the data were bounded by the laminar and turbulent predictions; 3) Stagnation region data for most conditions showed an augmentation above both nearby laminar data and the laminar predictions.

\section{E. Aftbody Comparisons}

Full-vehicle computations that included the crew module, model sting, and wake flow field were performed for only a limited set of cases ( $\alpha=28$ deg in AEDC Tunnel 9) because of the high computational costs of generating such solutions. Comparisons between wind tunnel data and predictions for these cases are shown in Figure 15 and Figure 16. The format for these plots is the same as that of the heat-shield plots except that boundary-layer parameters are not shown for the leeside $(z / R>0)$ portion of the crew module. The flow-field in this region was mostly separated and therefore the values of these parameters, which are defined in terms of an attached-wall boundary layer, were meaningless.

At Mach 8, the windside $(z / R<0)$ data for the two lower Reynolds numbers were $\sim 15 \%$ to $25 \%$ higher than laminar predictions, which was outside the estimated experimental uncertainty. However, these data were still much lower than turbulent predictions. At $R e_{\infty}=30.6 \times 10^{6} / \mathrm{ft}$, the data indicated transition midway along the body, and at the end of the body the data and turbulent predictions matched. For the highest Reynolds number of $\operatorname{Re}_{\infty}=$ $47.9 \times 10^{6} / \mathrm{ft}$ the data and turbulent predictions agreed to within the experimental uncertainty. At Mach 10 the laminar predictions matched the data for all cases. From these comparisons, two conclusions can be reached. First, that the flow from the heat-shield re-laminarized as it turned around the shoulder onto the command module and only transitioned again farther along the body. And second, that the algebraic turbulence models were as accurate for attached aftbody-flow (over the command module) as for the forebody flow (over the heat-shield).

\section{F. Data Correlations Between Wind Tunnels}

As shown previously, laminar heating distributions from each wind tunnel were nearly independent of Reynolds numbers when plotted in terms of the parameter $S t \times\left(R e_{\infty, \mathrm{D}}\right)^{1 / 2}$. However, as shown in Figure 17 for the $\alpha=28-\mathrm{deg}$ data from all tunnels, the distributions from each tunnel differed because the formulation in Eq. (1) does not account for the effects of different enthalpy levels in each facility. To account for this factor, the data were re-plotted in terms of a Stanton number based on the adiabatic wall-recovery enthalpy, where the recovery factor was approximated by the square-root of the Prandtl number as for a flat-plate (e.g. Ref. 14).

$$
S t_{r e c} \times\left(\operatorname{Re}_{\infty, D}\right)^{1 / 2}=q\left(\frac{\rho_{\infty} U_{\infty} D}{\mu_{\infty}}\right)^{1 / 2} / \rho_{\infty} U_{\infty}\left[\sqrt{\operatorname{Pr}}\left(h_{\infty}+\frac{U_{\infty}^{2}}{2}\right)-h_{w}\right]
$$

As shown in Figure 18 for the same test data, near-independence from Reynolds number and enthalpy for laminar data can be obtained with this formulation. Additional correlations are shown for the $\alpha=24$ and 32-deg cases in Figure 19 and Figure 20. The wind tunnel data reduction schemes utilized in this study do not typically output data in this format since the recovery factor is only an approximation. However, for the current configuration and test conditions this approximation is fairly accurate. 


\section{G. Transition Correlations}

The heating data obtained in this study can also be used in the analysis of boundary-layer transition. In these tests, the transition mechanism was "smooth-body" boundary-layer growth with running length. In flight however, transition will also be promoted by ablation roughening and blowing of its thermal protection system material. Because of the challenges associated with analysis of all the possible transition mechanisms, it is the defined policy of the CEV program to make a conservative assumption that the vehicle will experience turbulent flow throughout it's trajectory. Therefore the following results are presented for use in transition research, rather than for direct use by the CEV program.

With respect to leeside transition onset in the three data sets, a comparison can be made between a commonly used estimate of $R e_{\theta}=200$ for onset of transition and the computed values shown in Figure 12 through Figure 14. In the LaRC Mach 6 test, peak $R e_{\theta}$ values on the leeside were in the range of 200 to 350 and the experimental data were laminar or barely transitional. In the AEDC Tunne1 9, the Mach 10 peak values were between 100 and 450 and the data ranged from laminar to fully-turbulent, while the Mach 8 peak values varied from 400 to 900 and the data were transitional or fully-turbulent.

A more exact correlation of the transition onset data along the leeside centerline of the heat shield was also performed by extracting the values of $R e_{\theta}$ and $R e_{\theta} / M_{\mathrm{e}}$ at the onset locations from the flow-field solutions. These values are plotted vs. free-stream Reynolds numbers in Figure 21 and Figure 22. These plots encompass all Reynolds numbers and angles-of-attack at each of the three test Mach numbers. The average $R e_{\theta}$ value was 210 , which is close to the $R e_{0}=200$ criteria used in smooth-body transition analyses. However, the transition onset location for each Reynolds number varied with angle-of-attack, which led to the scatter seen in this plot. A better correlation can be formed by plotting $R e_{\theta} / M_{\mathrm{e}}$ vs. Reynolds number as shown in Figure 22 since the $M_{\mathrm{e}}$ term helps account for variations in local conditions with angle of attack.

In addition to the data collected from these tests, transition data from a similar blunt-body, the Mars Science Laboratory (MSL) heat-shield, was obtained in the same wind tunnels (Ref. 17 and 24) as well as in the CUBRC LENS (Ref. 24) and CalTech T5 (Ref. 25) facilities. The leeside centerline transition onset location values of $R e_{\theta}$ and $R e_{\theta} / M_{\mathrm{e}}$ from those tests are added to the CEV data in Figure 23 and Figure 24. The $R e_{\theta}$ values all fell within approximately the same range as for CEV with an average value of 226 . However, the $R e_{\theta} / M_{\mathrm{e}}$ data fell into three distinct bands: the perfect-gas air and $\mathrm{N}_{2} \mathrm{CEV}$ data, the perfect-gas air and $\mathrm{N}_{2} \mathrm{MSL}$ data, and the high-enthalpy $\mathrm{CO}_{2}$ data from CUBRC LENS and CalTech T5.

\section{H. Turbulent Heating Augmentation Ratios}

A final parameter of interest for CEV design purposes is the ratio of heating augmentation above laminar levels due to turbulence on the heat shield, $\phi_{\mathrm{T}}$, as defined in Eq. (5). Values of this ratio at each tunnel condition were extracted from the data for three points (Figure 25) on the model: on the heat shield immediately before the windside and leeside tangency points with the shoulder; and on the windward side of the crew module before the base of the vehicle. These values are plotted in Figure 26 to Figure 28 vs. $R_{\theta}$ values predicted for the wind tunnel conditions. Estimates for the extent of laminar, transitional, and turbulent behavior at each point are shown. Additionally, the value of $R e_{\theta}$ predicted in flight at the peak heating point along a typical lunar return mission trajectory is also given. At the leeside corner point, these data indicate that the boundary layer would be transitional with augmentation factors of up to three times the laminar level. At the windside corner, the boundary layer would still be laminar, as would the boundary layer at the crew module point. These results provide some evidence that the CEV design philosophy of assuming turbulent flow in flight throughout the trajectory does provide some conservatism. However, the data from these perfect-gas, smooth-body wind tunnel tests do not account for chemistry, roughness, or ablation effects and are thus not directly scaleable to flight conditions.

$$
\phi_{T}=\left[S t \times\left(\operatorname{Re}_{\infty, D}\right)^{1 / 2}\right]_{\text {measured }} /\left[S t \times\left(\operatorname{Re}_{\infty, D}\right)^{1 / 2}\right]_{\text {predicted,laminar }}
$$

\section{V. $\square$ Summary and Conclusions}

The convective aeroheating environment of the Project Orion Crew Exploration Vehicle has been studied through testing of a thermocouple-instrumented 7-inch diameter $(\sim 0.035$ scale $)$ model in AEDC Hypervelocity Wind Tunnel No. 9 Mach 8 and Mach 10 nozzles and the NASA LaRC 20-Inch Mach 6 Air Tunnel. Test conditions produced (as a function of free-stream Reynolds number) laminar, transitional and turbulent flow in the AEDC Tunnel 9 Mach 10 nozzle, transitional and turbulent flow in the AEDC Tunnel 9 Mach 8 nozzle, and laminar and transitional flow in the NASA LaRC 20-Inch Mach 6 Air Tunnel. For the transitional and turbulent cases, transition 
always began first on the leeside of the heat shield and increased to fully-developed turbulent flow on the leeside as Reynolds numbers were increased. A small region of transitional/turbulent flow also was observed on the windside between the stagnation region and shoulder for the highest Reynolds number conditions in AEDC Tunnel 9.

Computational predictions were generated for all wind tunnel test conditions and comparison made between the predictions and test data. Laminar data and predictions, and turbulent data and predictions, were generally found to agree to well within the estimated $\pm 12 \%$ experimental uncertainty. Transitional data were bounded by the fullylaminar and fully-turbulent predictions. The only region where significant differences were observed was around the stagnation point where the data showed augmentation above expected laminar levels.

The laminar experimental heating data from each facility were shown to correlate well (near Reynolds-number independence) when expressed in terms of the parameter $S t \times\left(R e_{\infty, \mathrm{D}}\right)^{1 / 2}$. Similarly, turbulent experimental heating data correlated well when the exponent on the Reynolds number was changed from 0.5 to 0.2. To account for the differences in enthalpy levels between the facilities a modified Stanton number was employed in which the adiabatic wall-recovery enthalpy, rather than the total enthalpy, was used. This formulation permitted a universal correlation of all three laminar data sets.

Transition onset locations on the leeside of the model were determined from the data and comparisons with predictions. The values of the boundary-layer parameters $R e_{\theta}$ and $R e_{\theta} / M_{\mathrm{e}}$ were extracted from the predictions at these onset locations. An average of $\operatorname{Re}_{\theta}=210$ was determined, however the scatter was fairly high. A better correlation of the data was found with a power-law fit to $R e_{\theta} / M_{\mathrm{e}}$. These transition data were also compared to a wide range of data obtained from the MSL program. The average transition-onset value of $R e_{\theta}$ only shifted slightly to 226, although again the scatter in the data was high. For the transition-onset value of $R e_{\theta} / M_{\mathrm{e}}$ it was found that the data fell into three distinct bands: perfect-gas air and $\mathrm{N}_{2}$ CEV data, perfect-gas air and $\mathrm{N}_{2}$ MSL data, and highenthalpy $\mathrm{CO}_{2} \mathrm{MSL}$ data.

Correlations were also generated for heating augmentation above laminar levels due to transition and turbulence. Ratios of measured heating levels to predicted laminar levels were generated and plotted against $R e_{\theta}$ for three points on the body. With respect to the peak-heating time along a preliminary lunar return trajectory for the CEV, these correlations indicated that the flow at the leeside shoulder of the heat shield would be transitional with a convective heating augmentation of up to 3.5 times laminar levels. The correlations also indicated that the flow at the heatshield windside corner and along the crew-module windside would be laminar.

These comparisons between computations and data helped to define uncertainties for computational methods used to predict laminar and turbulent convective heating levels in flight and have been incorporated into the "best practices" used in the vehicle design process. Also, the transition onset and heating augmentation correlations provided evidence that the design assumption of turbulence throughout the flight does indeed provide conservatism in the vehicle design, since these results indicated the flow would only be transitional at the peak-heating location along the trajectory. That conclusion is, of course, subject to change throughout the CEV development process as the trajectory evolves. Also, the effects of heat-shield ablation, roughness, and blowing must be taken into account, as the current data set only provides information on smooth-body flow-fields.

\section{VI. $\square$ References}

1.'NASA's Exploration Systems Architecture Study, Final Report," NASA TM-2005-214062, November, 2005.

${ }^{2}$ Marren, D., and Lafferty, J., "The AEDC Hypervelocity Wind Tunnel 9," Advanced Hypersonic Test Facilities, Progress in Aeronautics and Astronautics, Vol. 198, American Institute of Aeronautics and Astronautics, Reston, VA, 2002, pp. 467-477.

${ }^{3}$ Micol, J. R. "Langley Aerothermodynamic Facilities Complex: Enhancements and Testing Capabilities," AIAA Paper 98-0147, January 1998.

${ }^{4}$ Amar, A. J., Calvert, N. Horvath, T. J., Hollis, B. R., Berger, K. T., and Berry, S. A., "Protuberance Boundary Layer Transition Test for Project Orion CEV at Mach 6," AIAA Paper 2008-1227, 46 ${ }^{\text {th }}$ AIAA Aerospace Sciences Meeting and Exhibit, Reno, NV, Jan. 7-10, 2007.

${ }^{5}$ Liechty, D. S., "Aerothermodynamic Testing of Protuberances and Penetrations on the NASA Cycle I Crew Exploration Vehicle Heat Shield in the NASA Langley 20-Inch Mach 6 Air Tunnel: Test 6918", NASA EG-CAP-06-155, November 2006.

${ }^{6}$ Berger, K. T., "Aerothermodynamic Testing of the Cycle I Crew Exploration Vehicle Crew Module in the LaRC 20-Inch Mach 6 and 31-Inch Mach 10 Tunnels," AIAA Paper 2008-1225, $46^{\text {th }}$ AIAA Aerospace Sciences Meeting and Exhibit, Reno, NV, Jan. 7-10, 2007.

${ }^{7}$ Berry, S. A., Bouslog, S. A., Brauckman, G. J. and Caram, J. M., "Shuttle Orbiter Experimental Boundary-Layer Transition Results with Isolated Roughness," Journal of Spacecraft \& Rockets, Vol. 35, No. 3, May-June 1998, pp. 241-248.

${ }^{8}$ Burns, G. W., Scroger, M. G., Strouse, G. F., Croarkin, M. C., and Guthrie, W. F., "Temperature-Electromotive Force Reference Functions and Tables for the Letter-Designated Thermocouple Types Based on ITS-90," NIST Monograph 175, 1993.

${ }^{9}$ Hedlund, E. R., Hill, J. A. F., Ragsdale, W. C., and Voisinet, R. L. P., "Heat Transfer Testing in the NSWC Hypervelocity Wind Tunnel Utilizing Co-Axial Surface Thermocouples," Naval Surface Weapons Center - NSWC-MP 80-151, March 1980. 
${ }^{10}$ Boyd, C. F., and Howell, A., "Numerical Investigation of One-Dimensional Heat-Flux Calculations," Naval Surface Warfare Center NSWCDD/TR-94/1 14, October 1994.

${ }^{11}$ Hollis, B. R., "User's Manual for the One-Dimensional Hypersonic Aero-Thermodynamic (1DHEAT) Data Reduction Code," NASA CR-4691, August 1995.

${ }^{12}$ Hollis, B. R., and Collier, A. S., "Turbulent Aeroheating Testing of Mars Science Laboratory Entry Vehicle in Perfect-Gas Nitrogen," AIAA Paper 2007-1228, 45 ${ }^{\text {th }}$ AIAA Aerospace Sciences Meeting and Exhibit, Reno, NV, Jan. 8-11, 2007.

${ }^{13}$ Coblish, J. C., "Aerothermal Measurement Improvements Using Coaxial Thermocouples at AEDC Hypervelocity Wind Tunnel No. 9," AIAA Paper 2007-1467, 45 ${ }^{\text {th }}$ AIAA Aerospace Sciences Meeting and Exhibit, Reno, NV, Jan. 8-11, 2007.

${ }^{14}$ Anderson, J. D. Jr., Hypersonic and High-Temperature Gas Dynamics, McGraw-Hill Book Company, New York, 1989.

${ }^{15}$ Gnoffo, P. A., "An Upwind-Biased, Point-Implicit Algorithm for Viscous, Compressible Perfect-Gas Flows," NASA TP-2953, February 1990 .

${ }^{16}$ Cheatwood, F. M., and Gnoffo, P. A., "User's Manual for the Langley Aerothermodynamic Upwind Relaxation Algorithm (LAURA)," NASA TM 4674, April, 1996.

${ }^{17}$ Hollis, B. R., and Liechty, D. S., "Transition Due to Heat-Shield Cavities on a Mars Entry Vehicle," Journal of Spacecraft and Rockets, Vol. 43., No. 2, March-April 2006, pp. 354-366.

${ }^{18}$ Roe, P. L., "Approximate Riemann Solvers, Parameter Vectors and Difference Schemes," Journal of Computational Physics, Vol. 43, No. 2, 1981, pp. 357-372.

${ }^{19}$ Harten, A., "High Resolution Schemes for Hyperbolic Conservation Laws," Journal of Computational Physics, Vol. 49, No. 3, 1983, pp. 357-393.

${ }^{20}$ Yee, H. C., "On Symmetric and Upwind TVD Schemes," NASA TM 88325, 1990.

${ }^{21}$ Brown, J. L., "Turbulence Model Validation for Hypersonic Flows," AIAA Paper 2002-3308, 8 ${ }^{\text {th }}$ AIAA/ASME Joint Thermophysics and Heat Transfer Conference, St. Louis, MO. June 24-26, 2002.

${ }^{22}$ Shimshi, J. P. and Walberg, G. D., "An Investigation of Aerodynamic Heating to Spherically Blunted Cones at Angle of Attack," AIAA Paper 1993-2764, $28^{\text {th }}$ AIAA Thermophysics Conference, Orlando, FL, January 6-9, 1993.

${ }^{23}$ Petersen, F. Server, D., and Carroll, H. "Heat Transfer and Pressure Distributions at $M=8$ on 0.029 Scale Models of the Viking Entry Vehicle," NASA CR-132413, July 1972.

${ }^{24}$ Hollis, B. R., Liechty, D. S., Wright, M. J., Holden, M. S., Wadhams, T. P., and MacLean, M., "Transition Onset and Turbulent Heating Measurements for the Mars Science Laboratory Entry Vehicle," AIAA Paper 2005-1437, 43 ${ }^{\text {rd }}$ Aerospace Sciences Meeting and Exhibit, Reno, NV, January 10-13, 2007.

${ }^{25}$ Wright, M. J., Olejniczak, J. Brown, J. L., Homung, H. G., and Edquist, K. T., "Modeling of Shock Tunnel Aeroheating Data on the Mars Science Laboratory Aeroshell," Journal of Thermophysics and Heat Transfer, Vol. 20, No. 4, October-December 2006, pp. 641-646. 

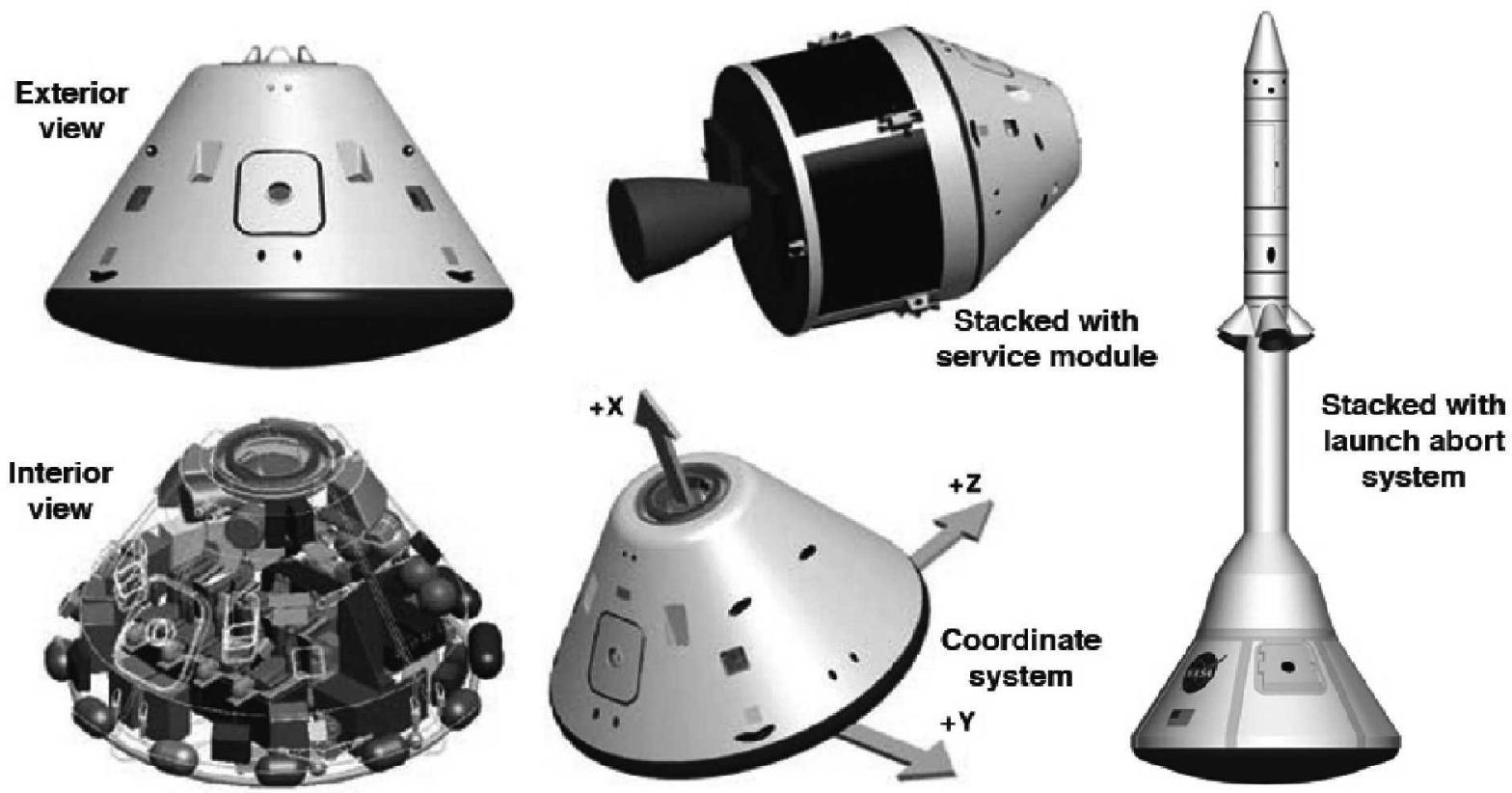

Figure 1. NASA Crew Exploration Vehicle (conceptual artwork) 

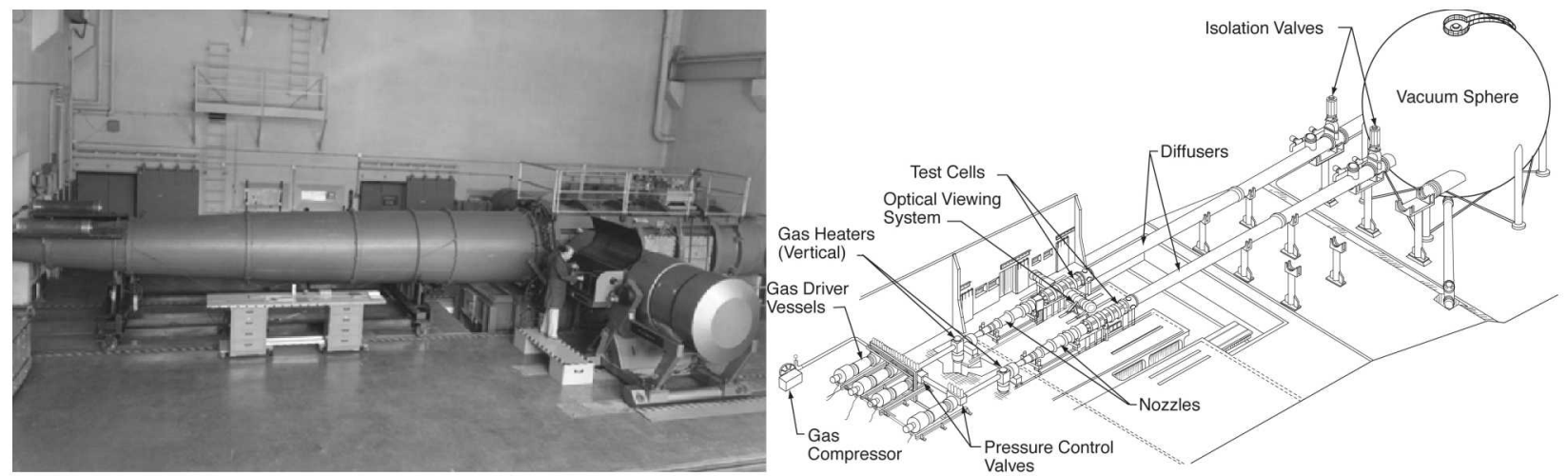

Figure 2. AEDC Tunnel 9 Photograph and Schematic 


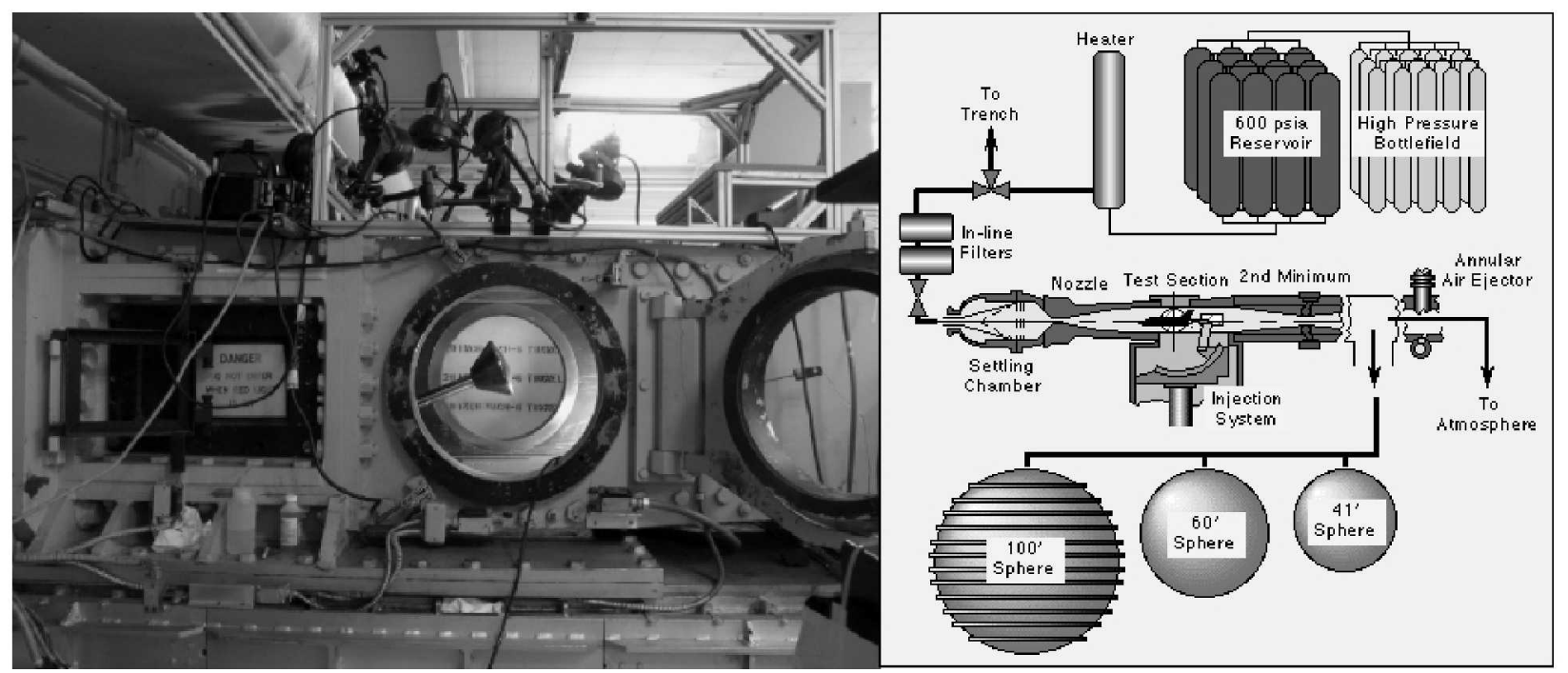

Figure 3. NASA LaRC 20-Inch Mach 6 Air Tunnel Photograph and Schematic 


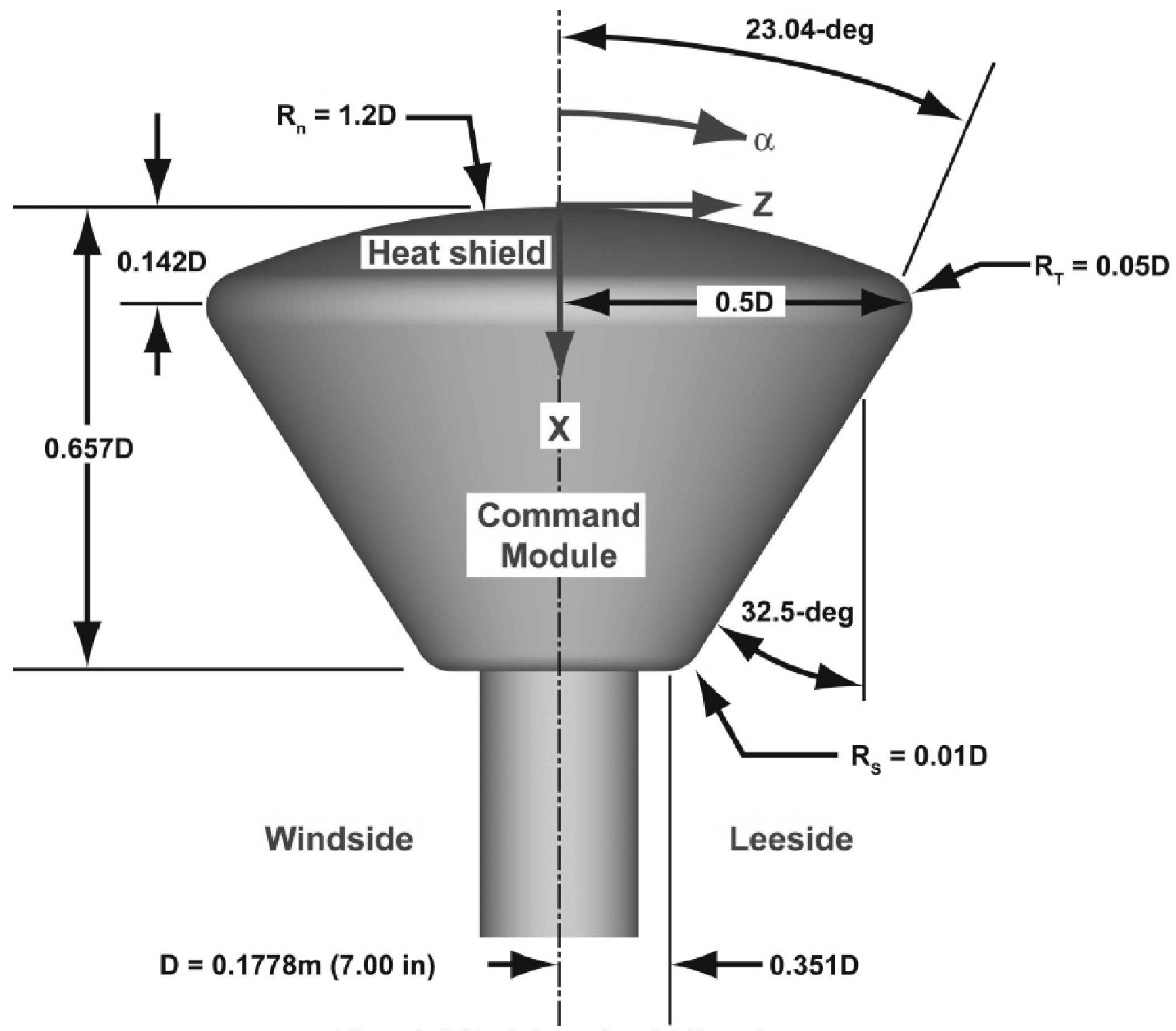

Figure 4. CEV wind tunnel model dimension 


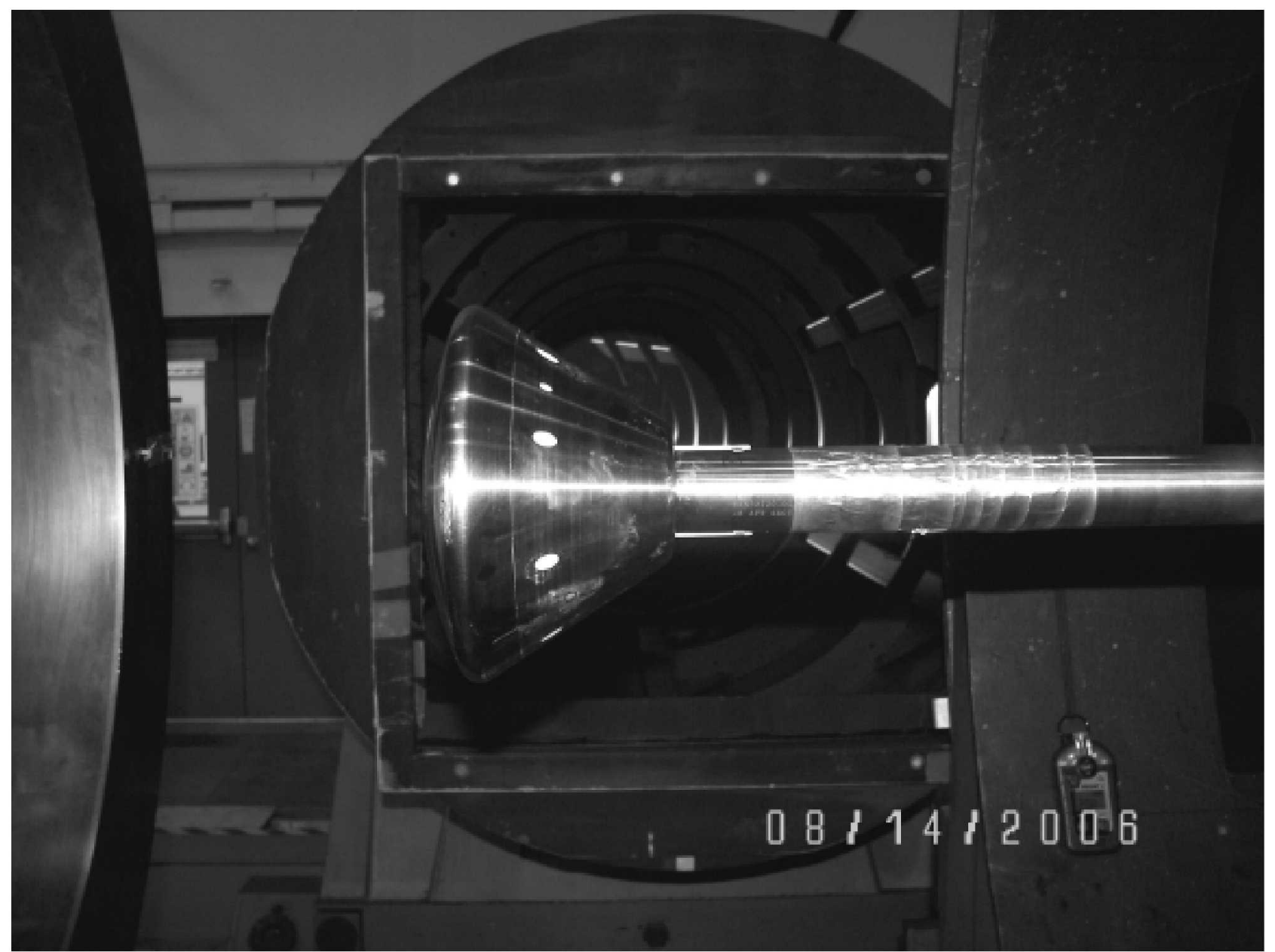

Figure 5. CEV model installed in AEDC Tunnel 9 (test section opened for viewing) 


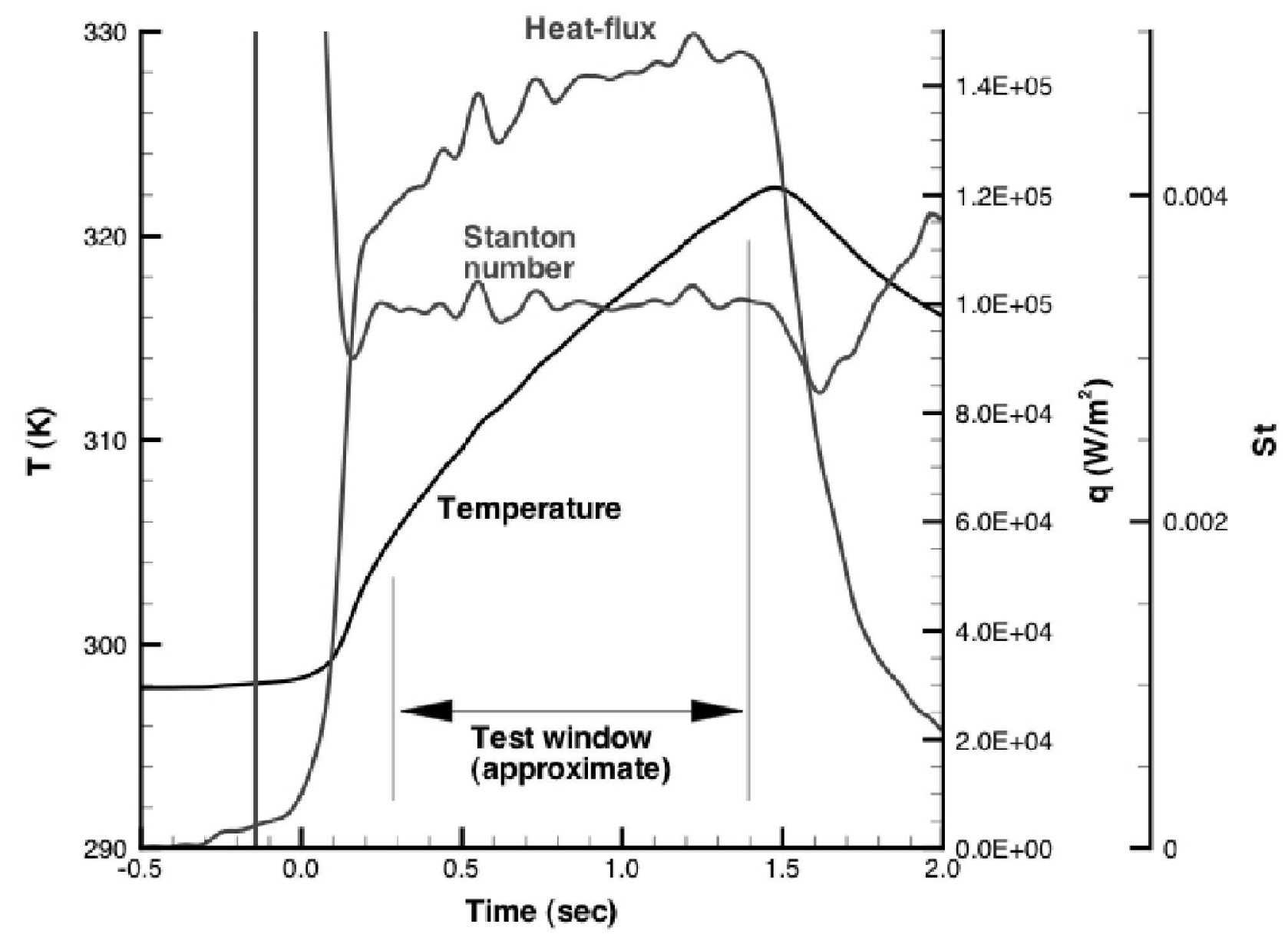

Figure 6. Sample time-histories of temperature, heat-flux and Stanton-number data from AEDC Tunnel 9 test of CEV model 


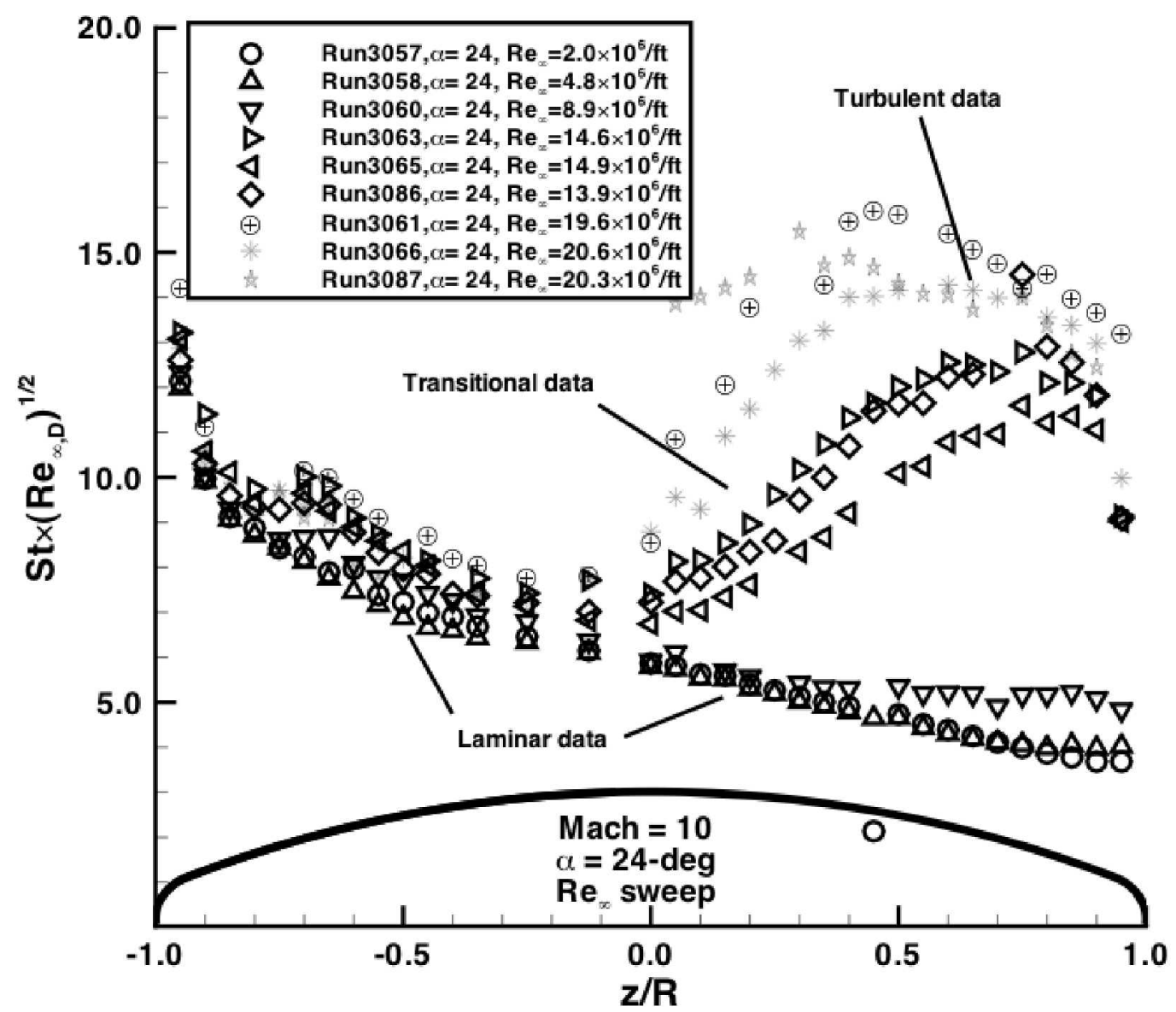

Figure 7. Correlation of laminar data using $\operatorname{St} \times\left(\operatorname{Re}_{\infty, \mathrm{D}}\right)^{(1 / 2)}$ parameter 


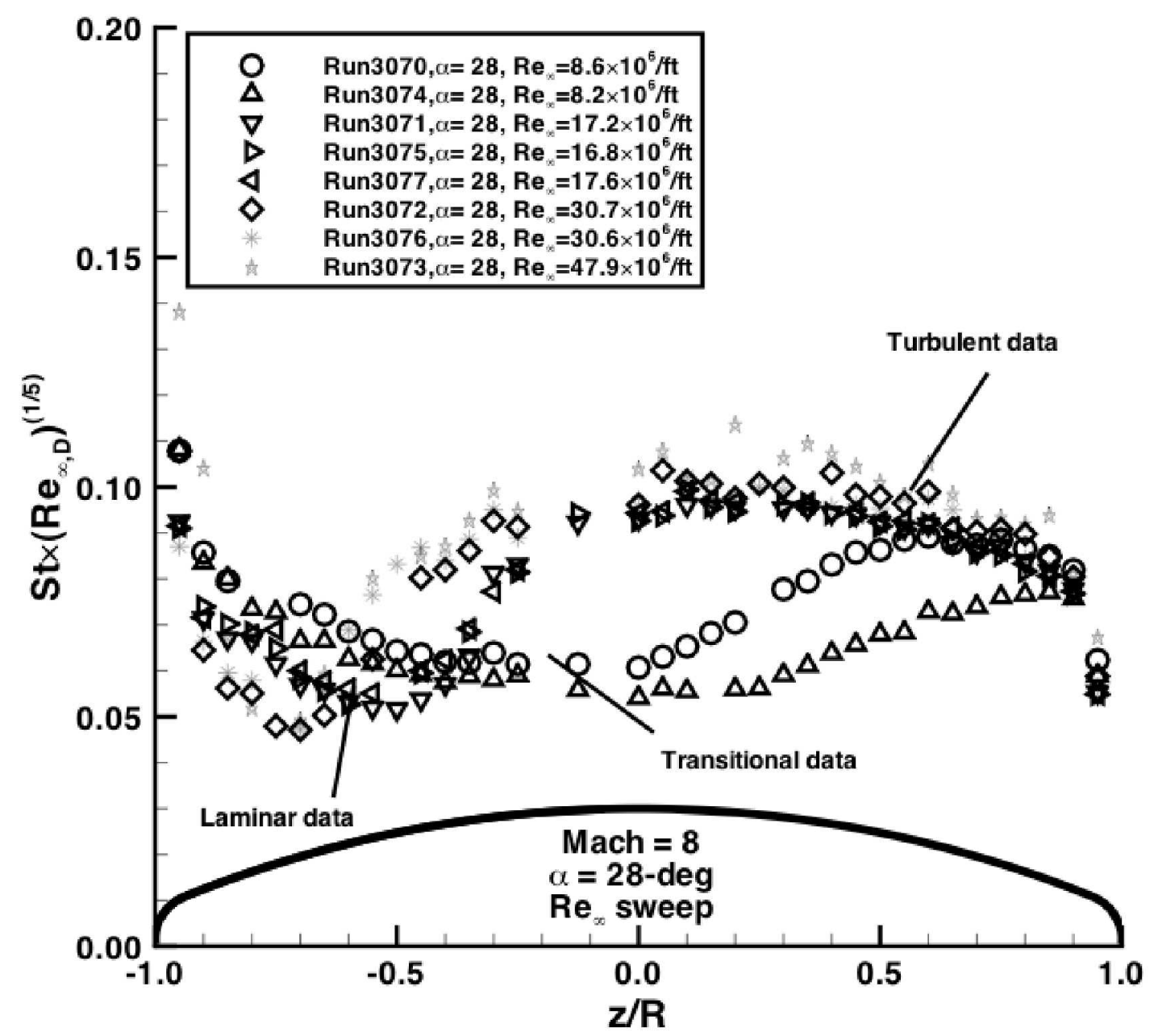

Figure 8. Correlation of turbulent data using $\operatorname{St} \times\left(\operatorname{Re}_{\infty, \mathrm{D}}\right)^{(1 / 5)}$ parameter 


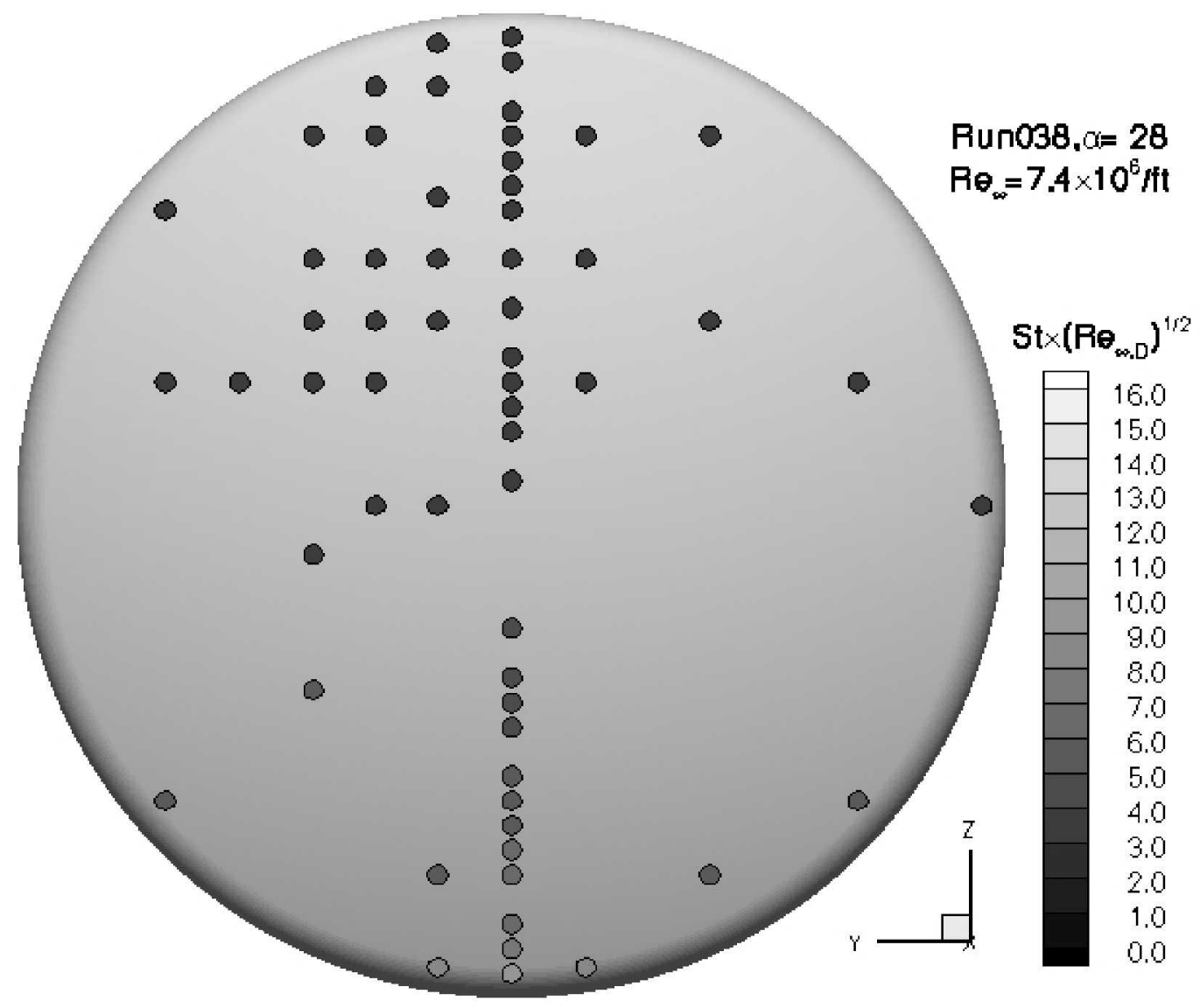

Figure 9. Sample LaRC Mach 6 Data 


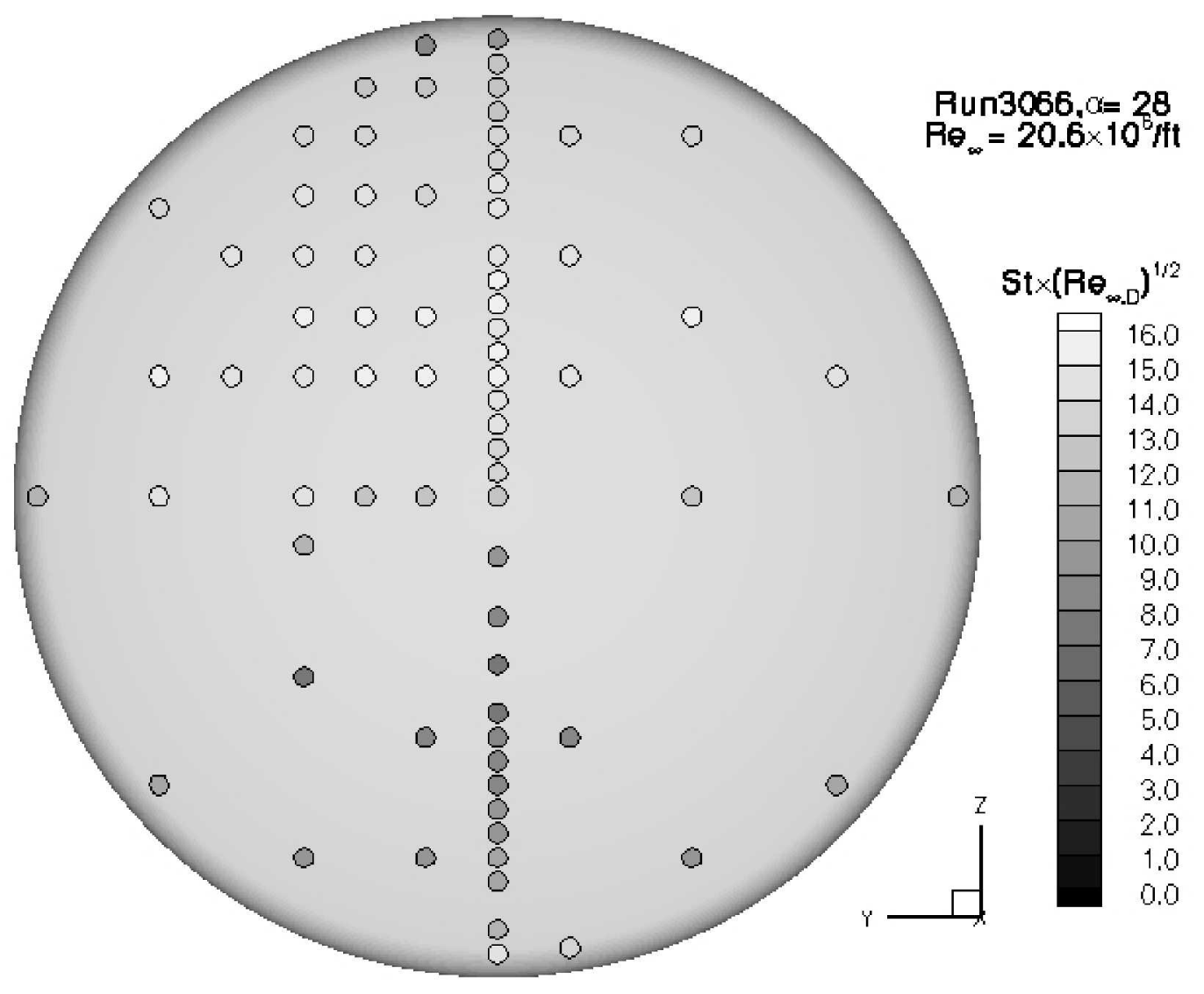

Figure 10. Sample AEDC Mach 10 Data 


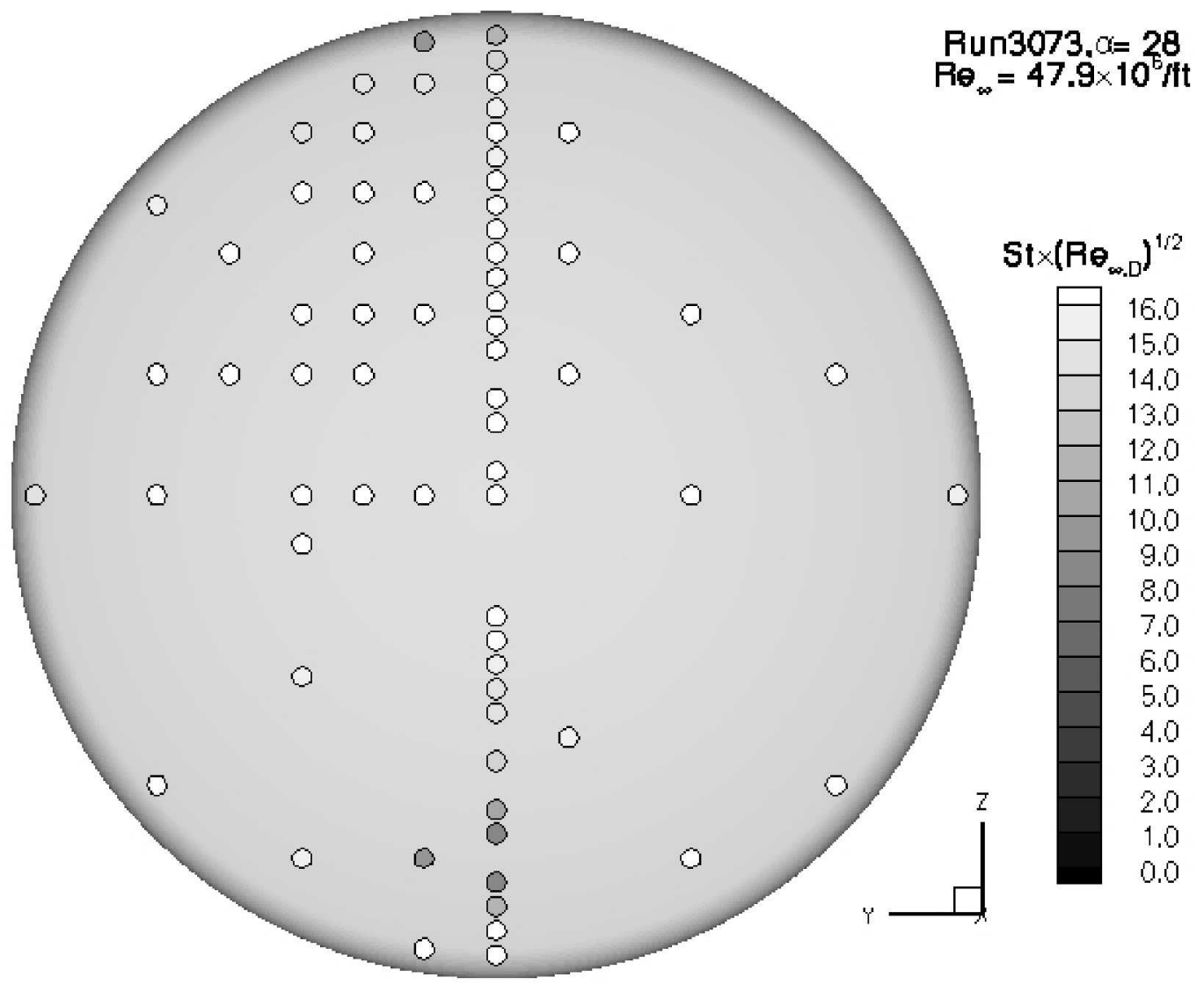

Figure 11. Sample AEDC Mach 8 Data 

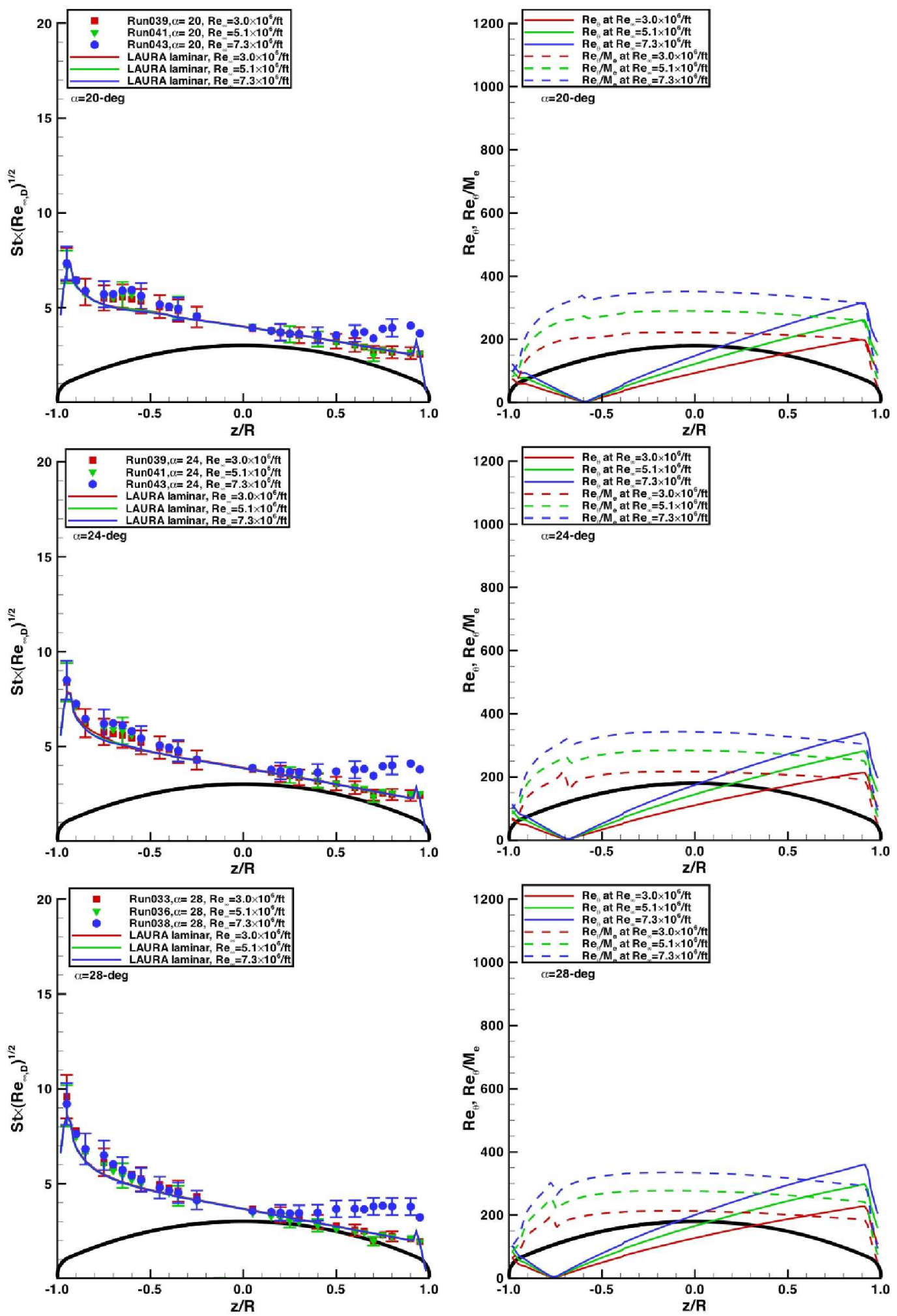

Figure 12. Forebody Heating and Boundary-Layer Parameters, 20-Inch Mach 6 Air, $\alpha=20$, 24, and 28-deg 

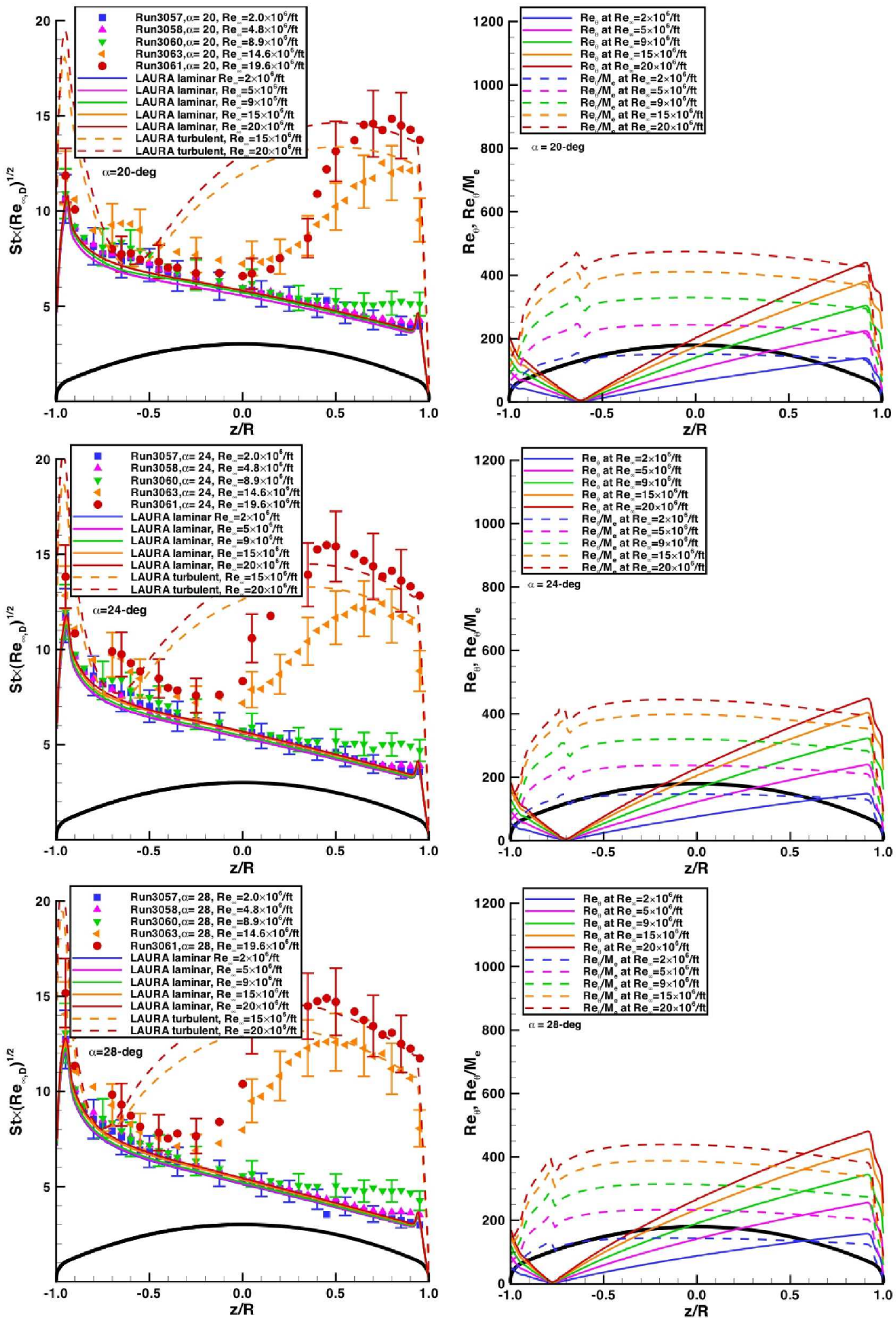

Figure 13. Forebody Heating and Boundary-Layer Parameters, AEDC Tunnel 9, Mach 10 nozzle, $\alpha=$ 20, 24, 28-deg 

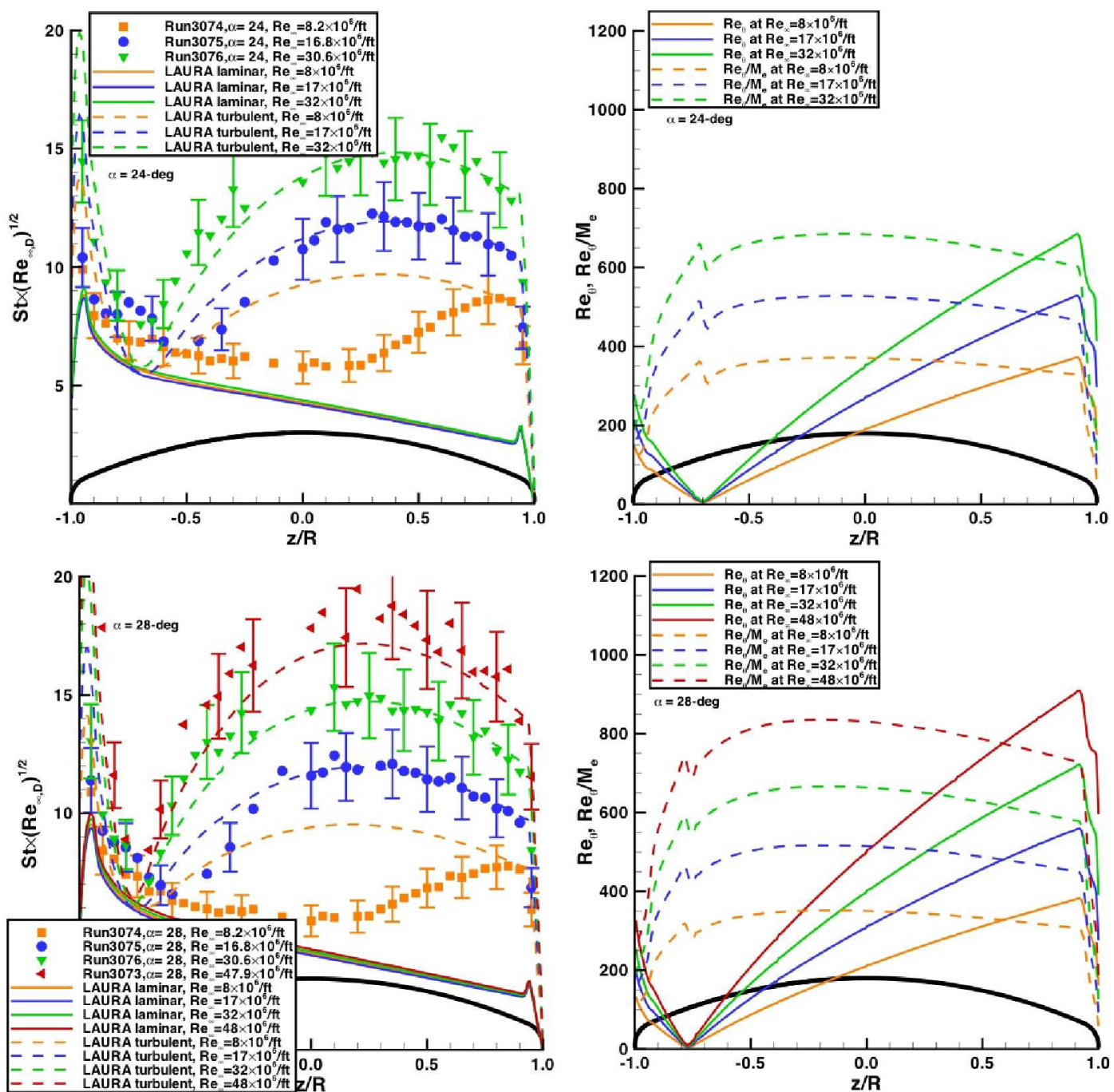

Figure 14. Forebody Heating and Boundary-Layer Parameters, AEDC Tunnel 9, Mach 8 nozzle, $\alpha=24$ and 28-deg 

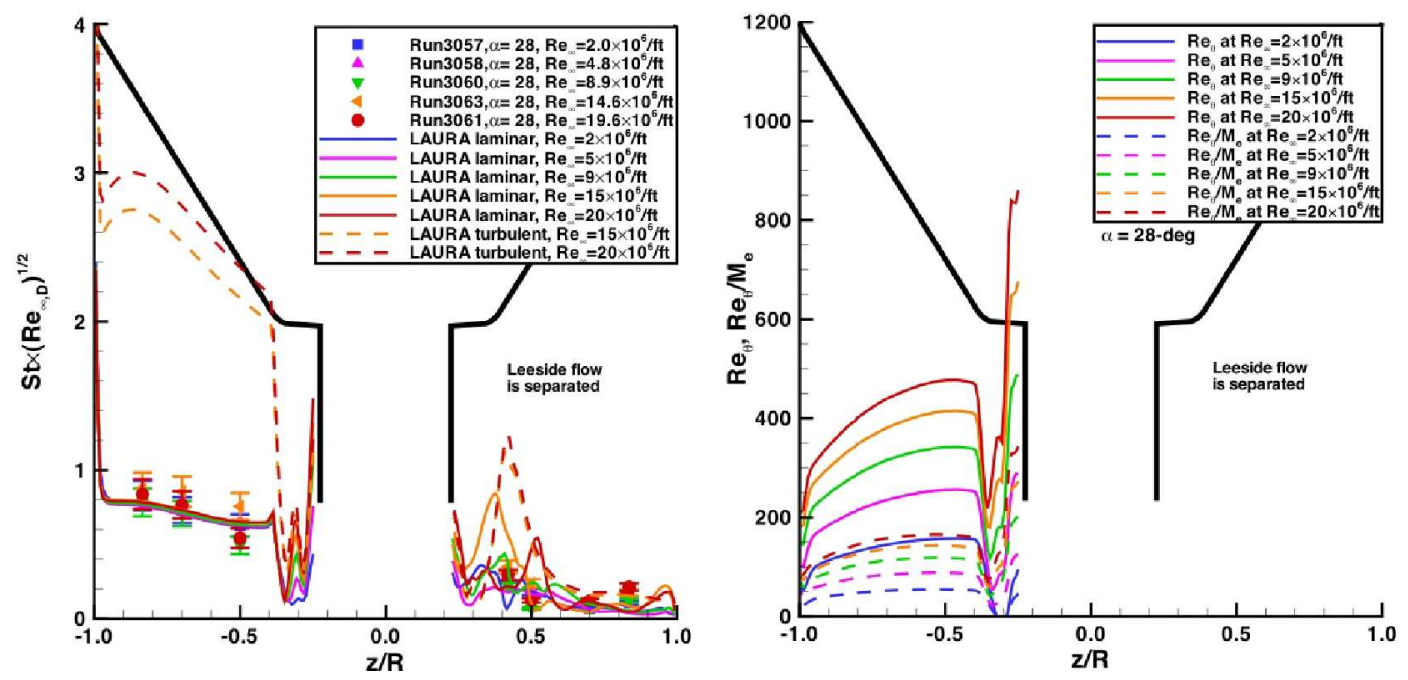

Figure 15. Aftbody Heating and Boundary-Layer Parameters, AEDC Tunnel 9, Mach 10 nozzle, $\alpha=28-d e g$ 

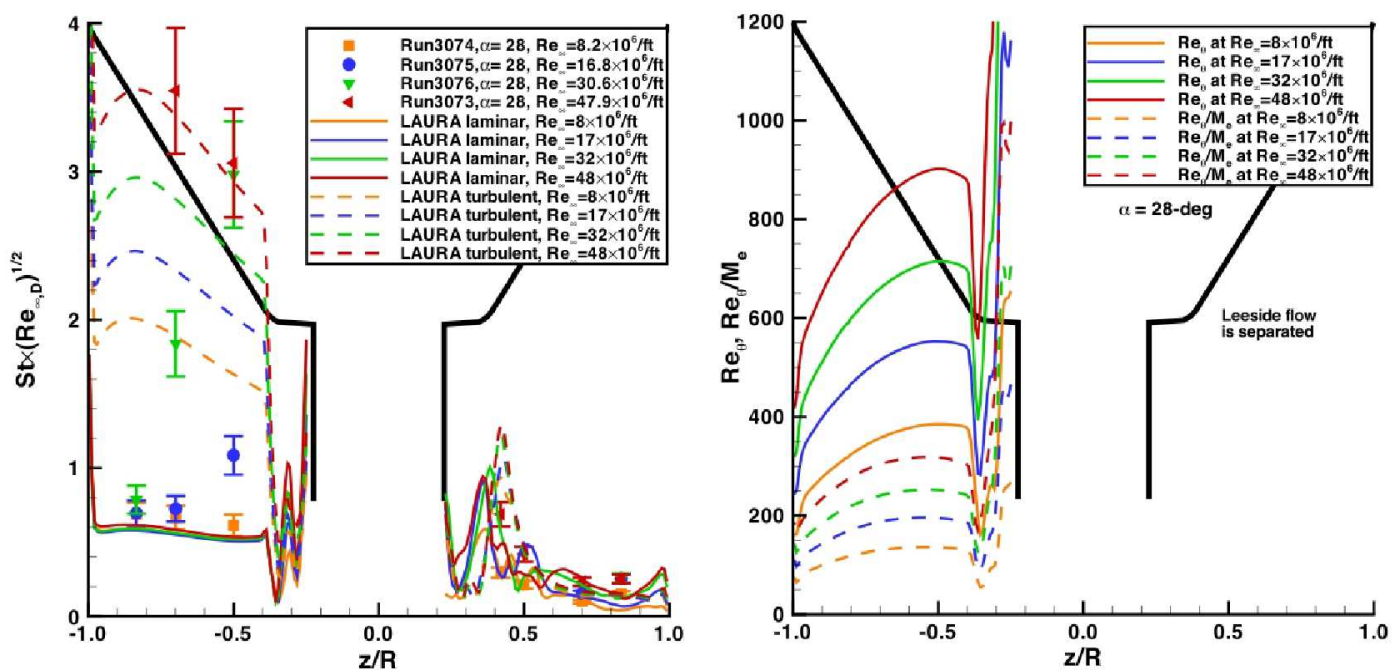

Figure 16. Aftbody Heating and Boundary-Layer Parameters, AEDC Tunnel 9, Mach 8 nozzle, $\alpha=28$-deg 


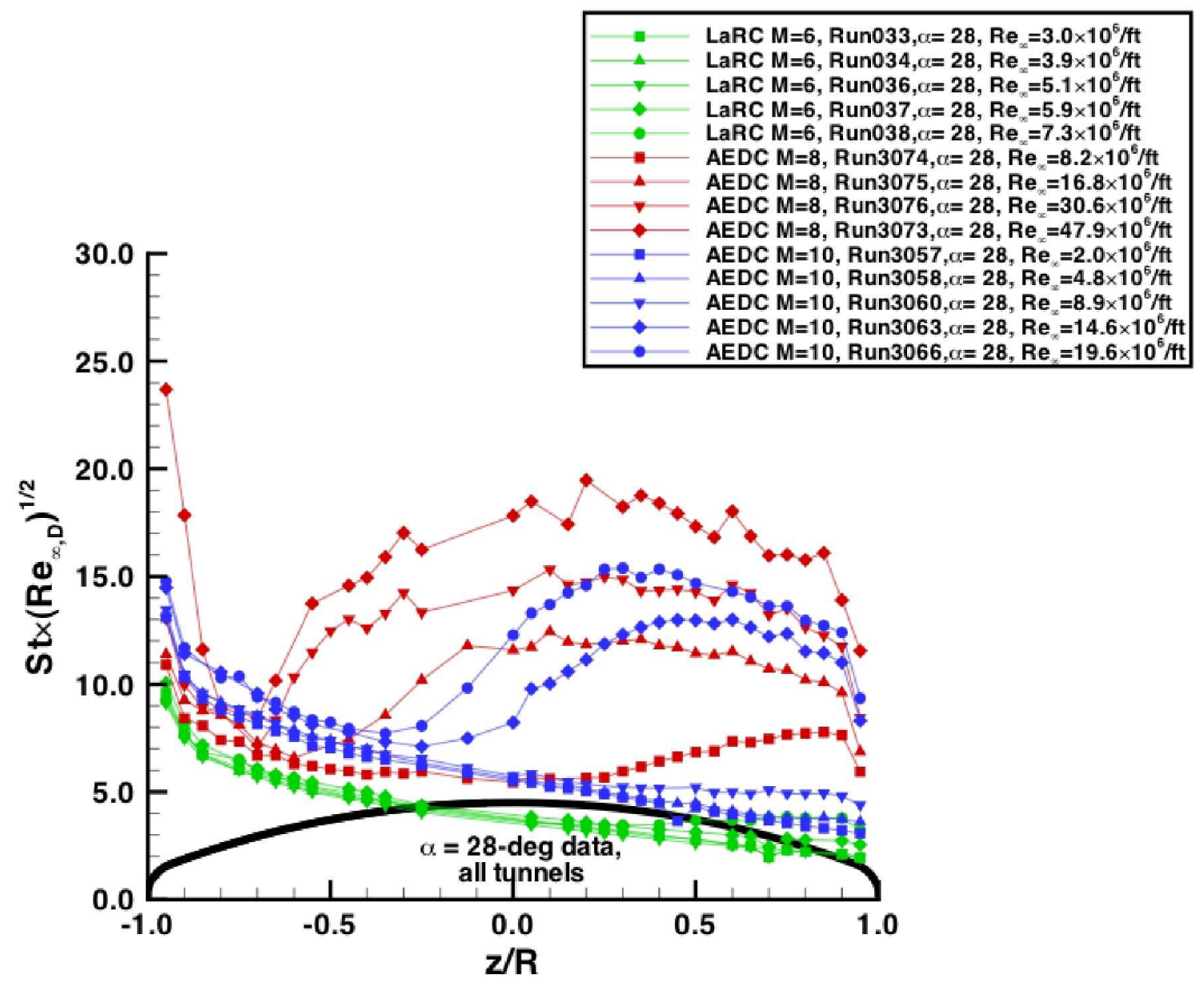

Figure 17. $\alpha=28$-deg distributions using total enthalpy 


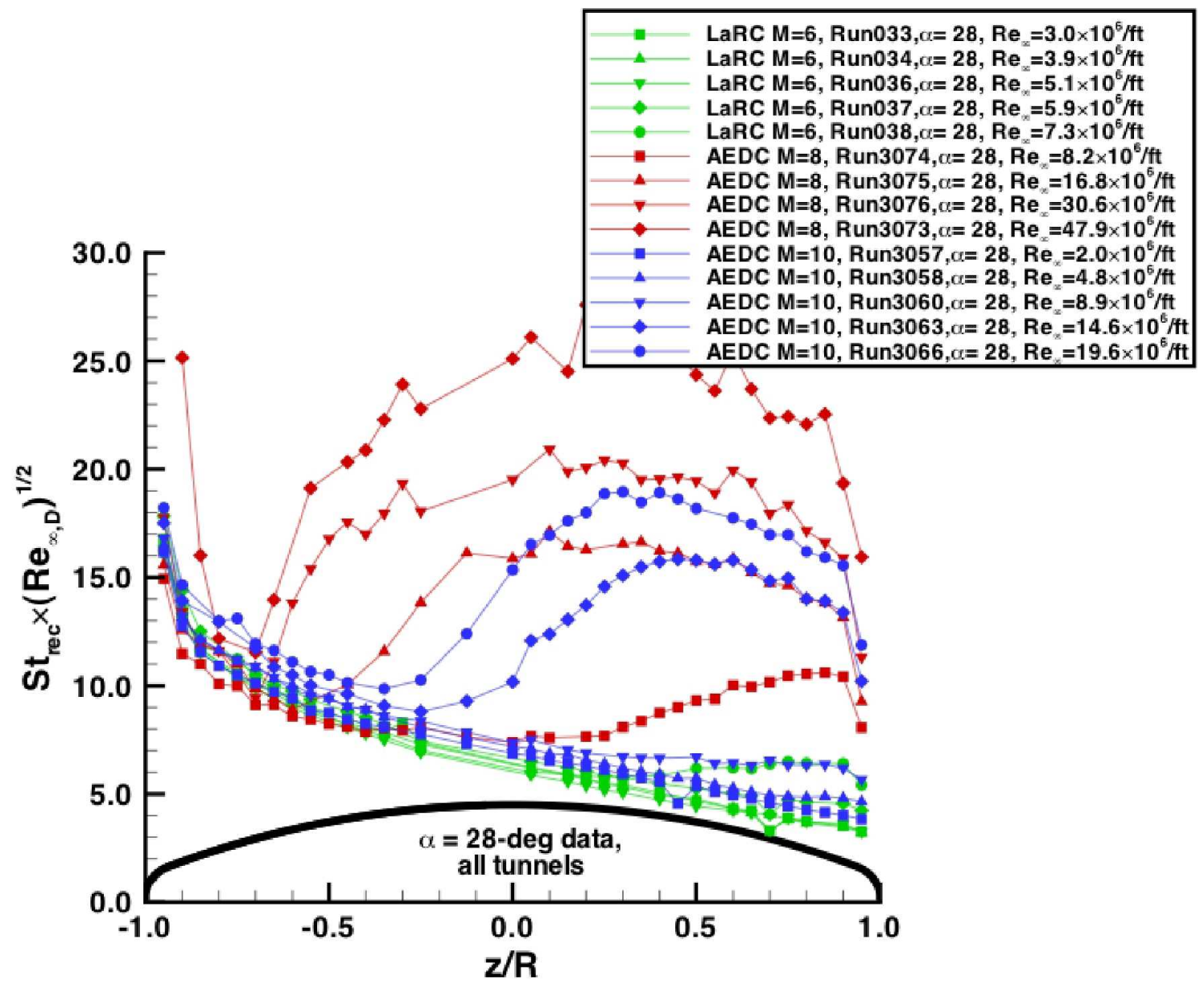

Figure 18. $\alpha=28-d e g$ distributions using adiabatic wall enthalpy 


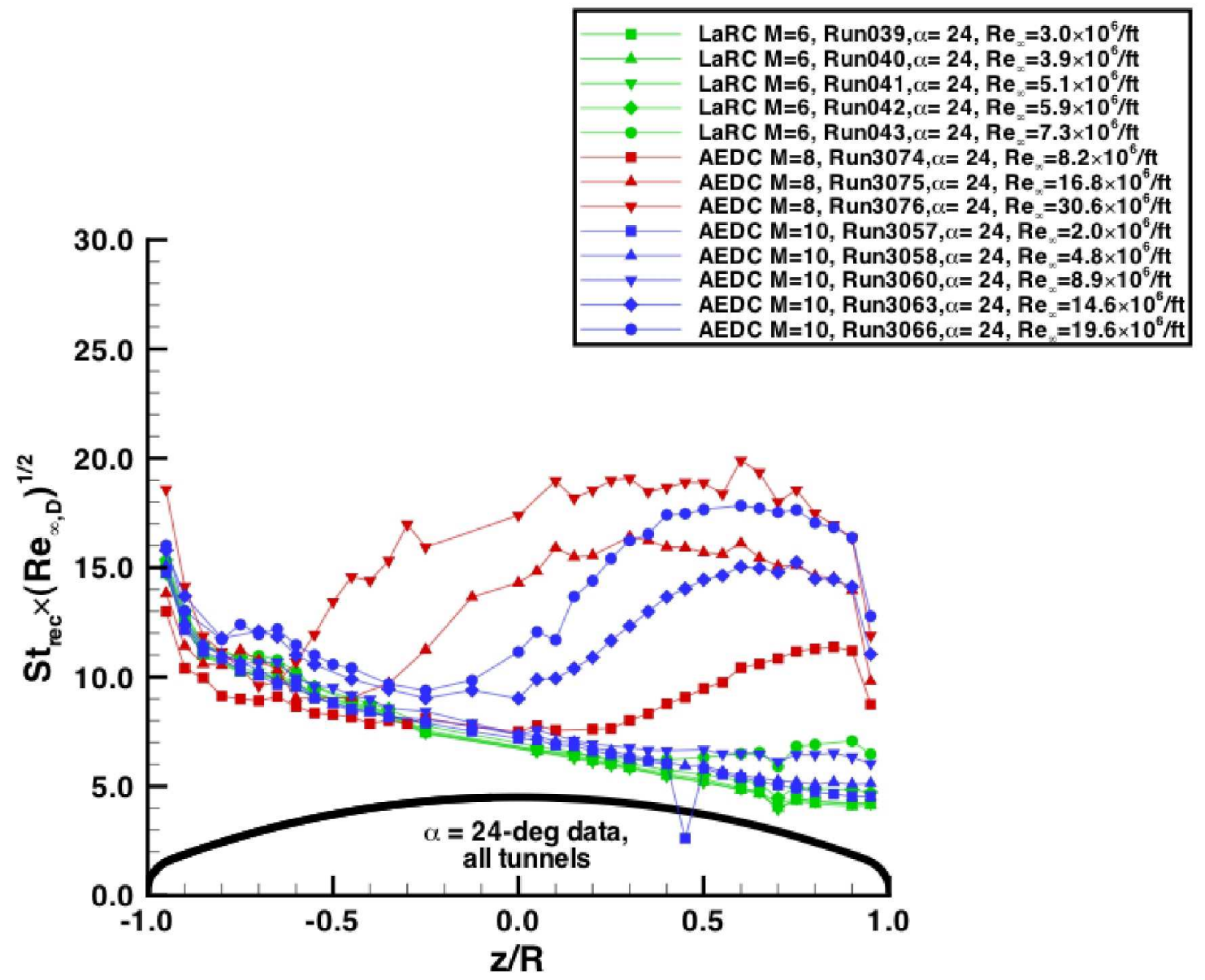

Figure 19. $\alpha=24-$ deg distributions using adiabatic wall enthalpy 


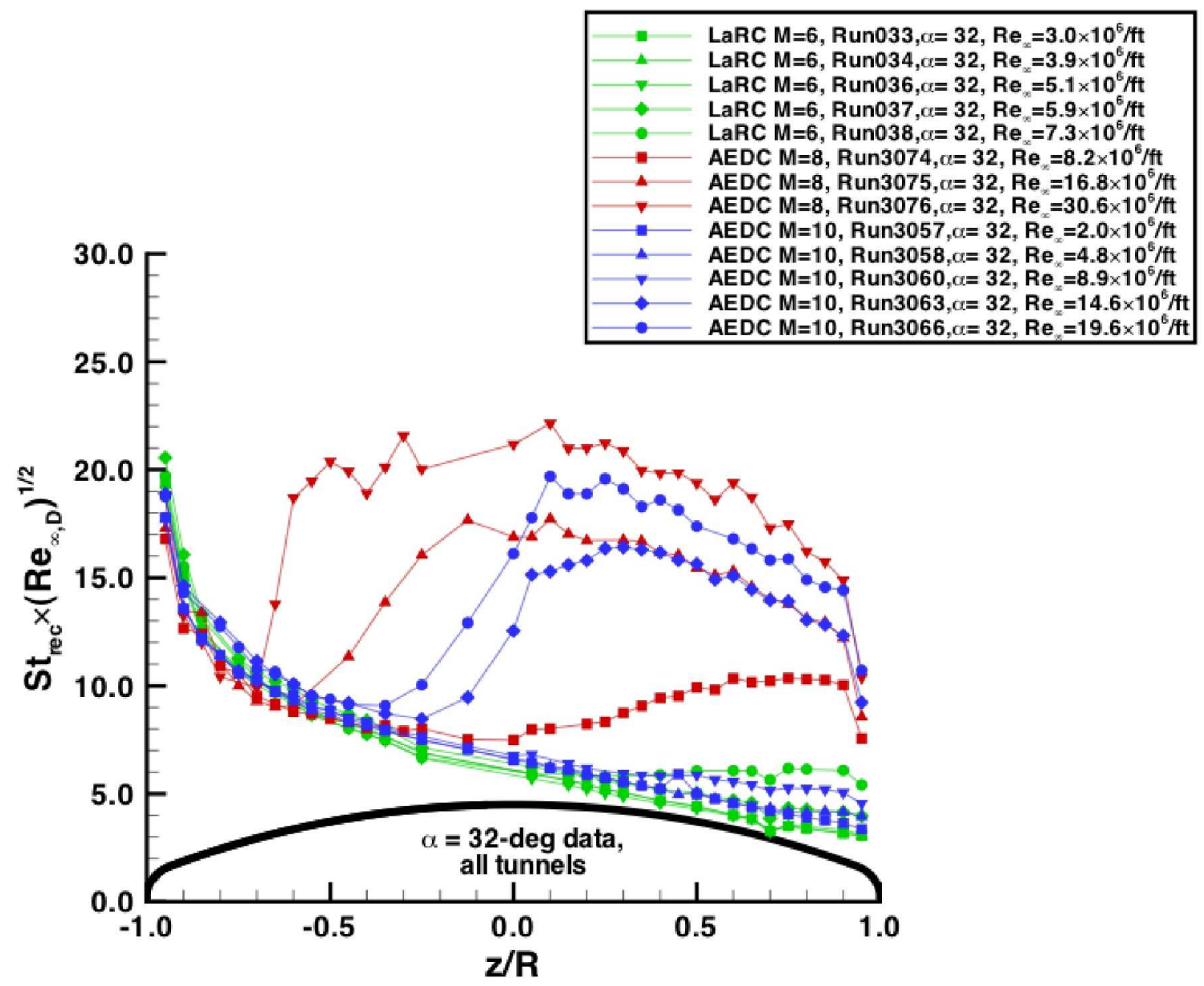

Figure 20. $\alpha=32-$ deg distributions using adiabatic wall enthalpy 


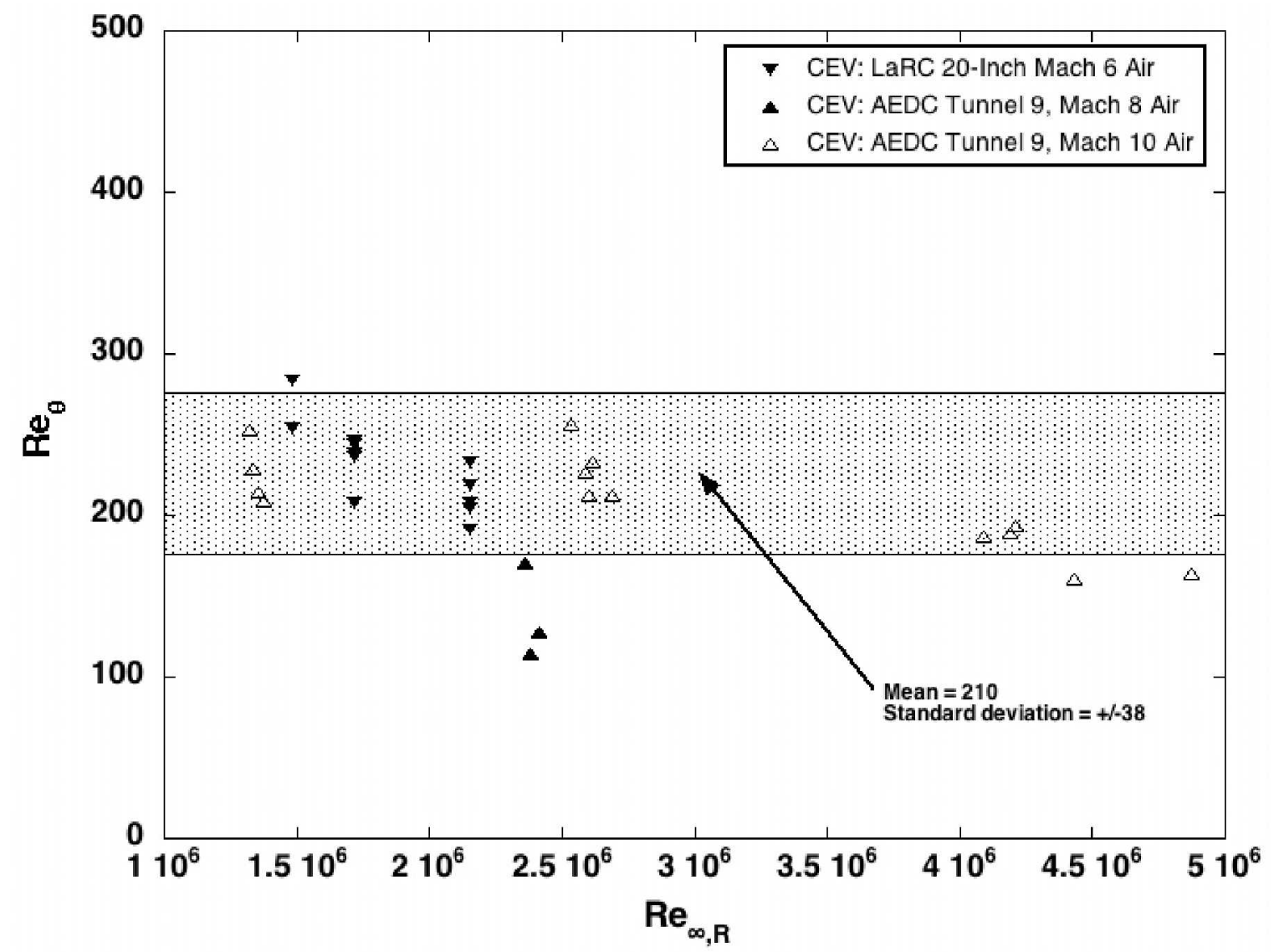

Figure 21. Transition onset values of $\boldsymbol{R e}_{\theta}$ 


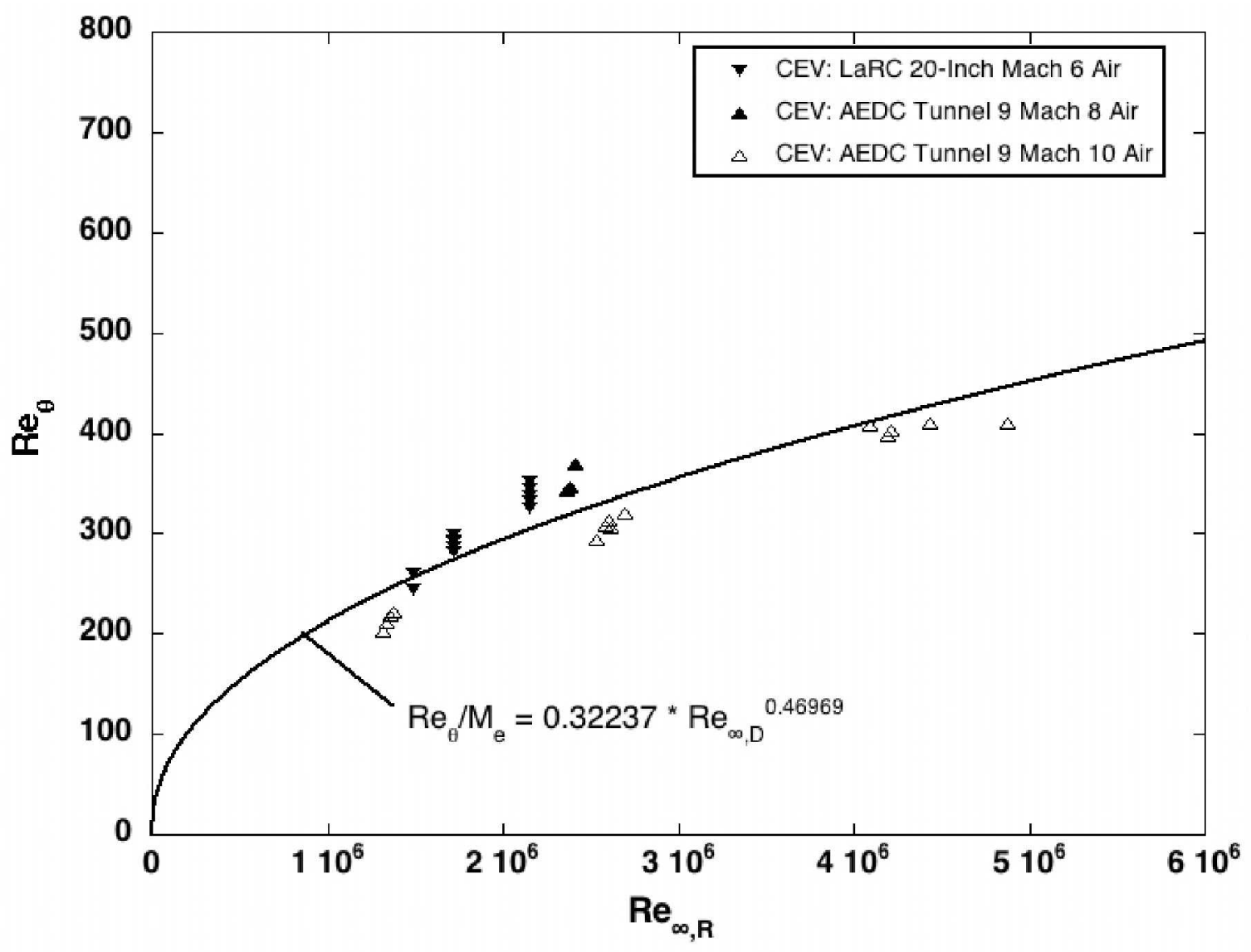

Figure 22. Transition onset values of $\boldsymbol{R e}_{\theta} / \boldsymbol{M}_{\mathrm{e}}$ 


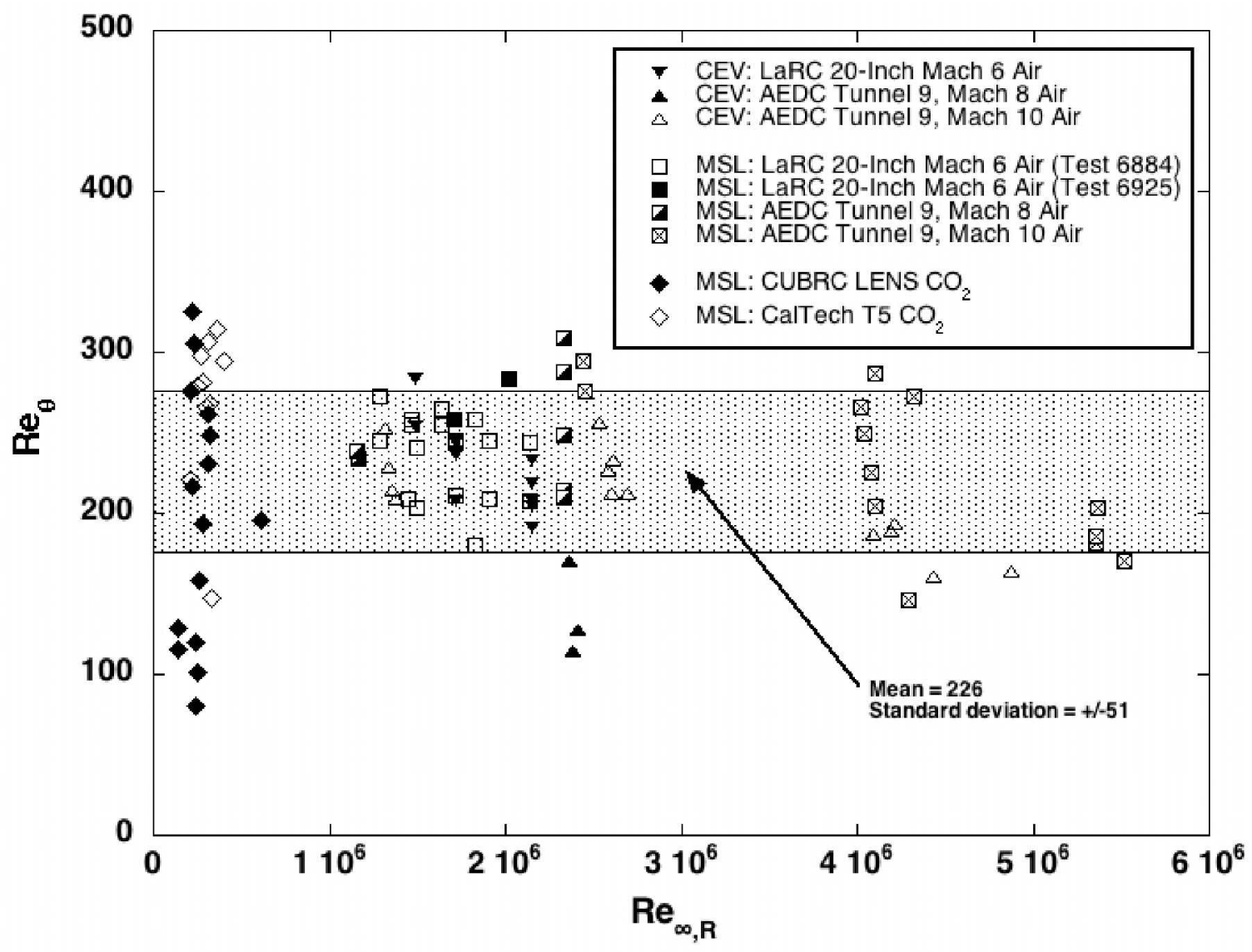

Figure 23. Transition onset values of $R e_{\theta}$ with additional MSL data added 


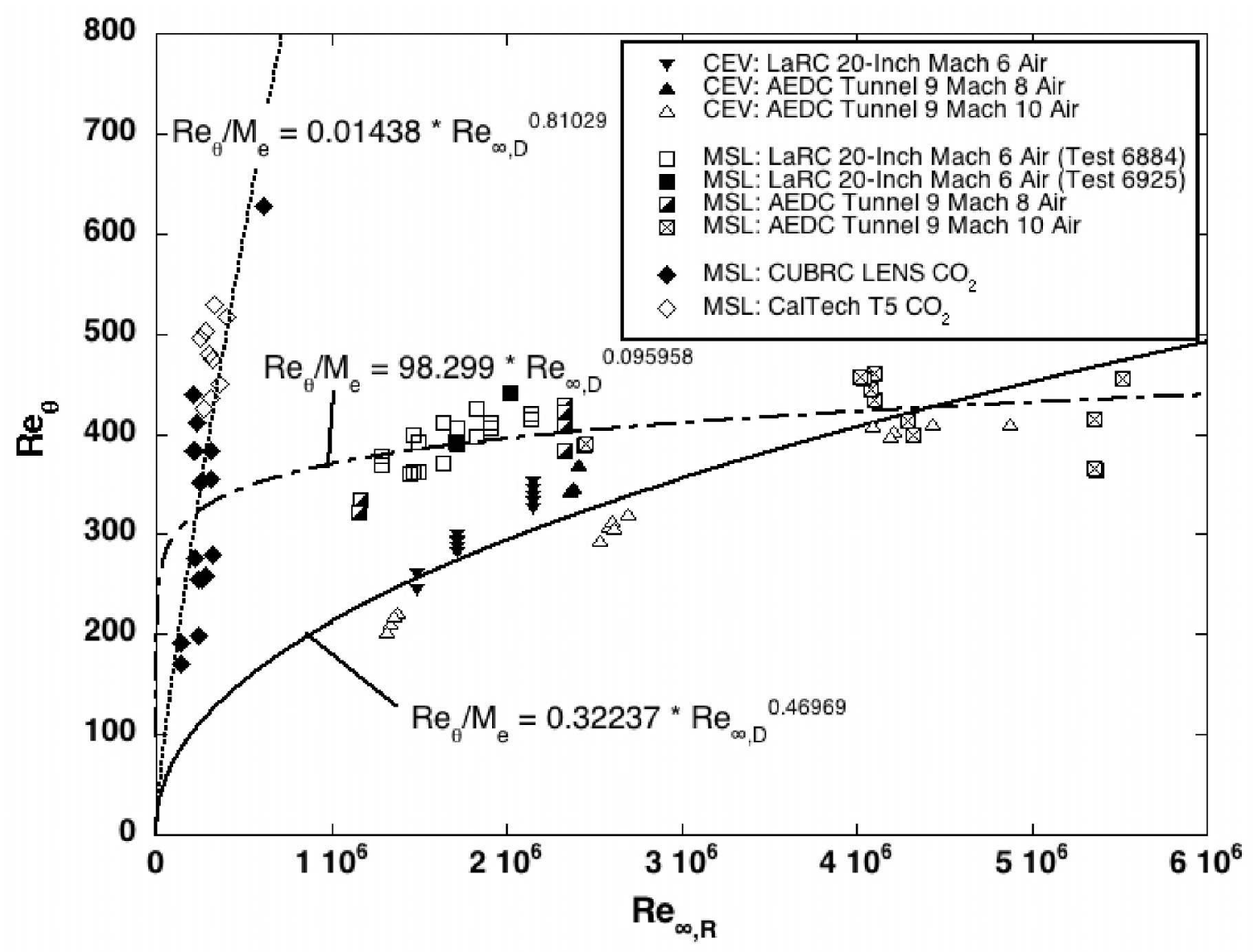

Figure 24. Transition onset values of $\operatorname{Re}_{\theta} / M_{\mathrm{e}}$ with additional MSL data added 


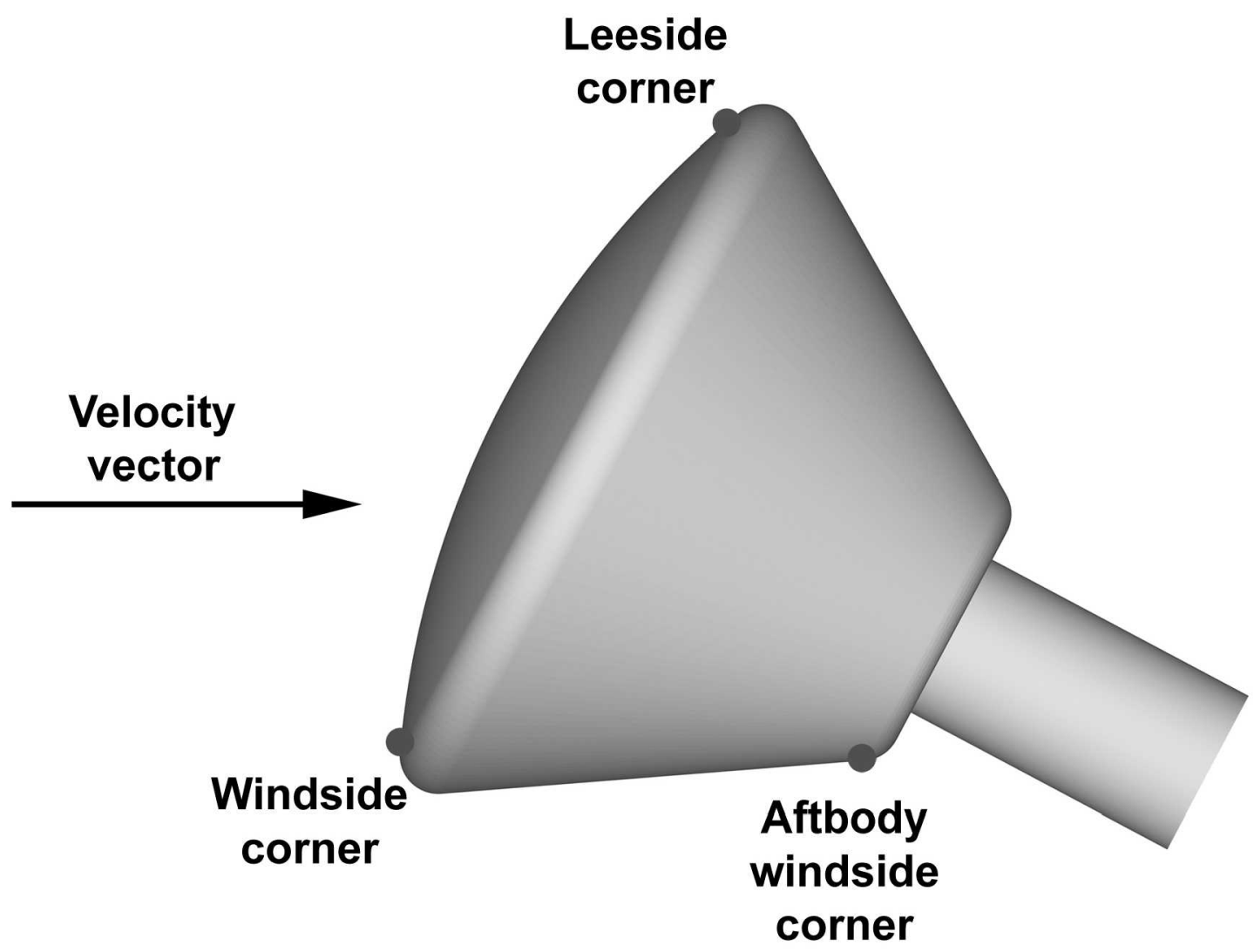

Figure 25. Body points for augmentation ratio 


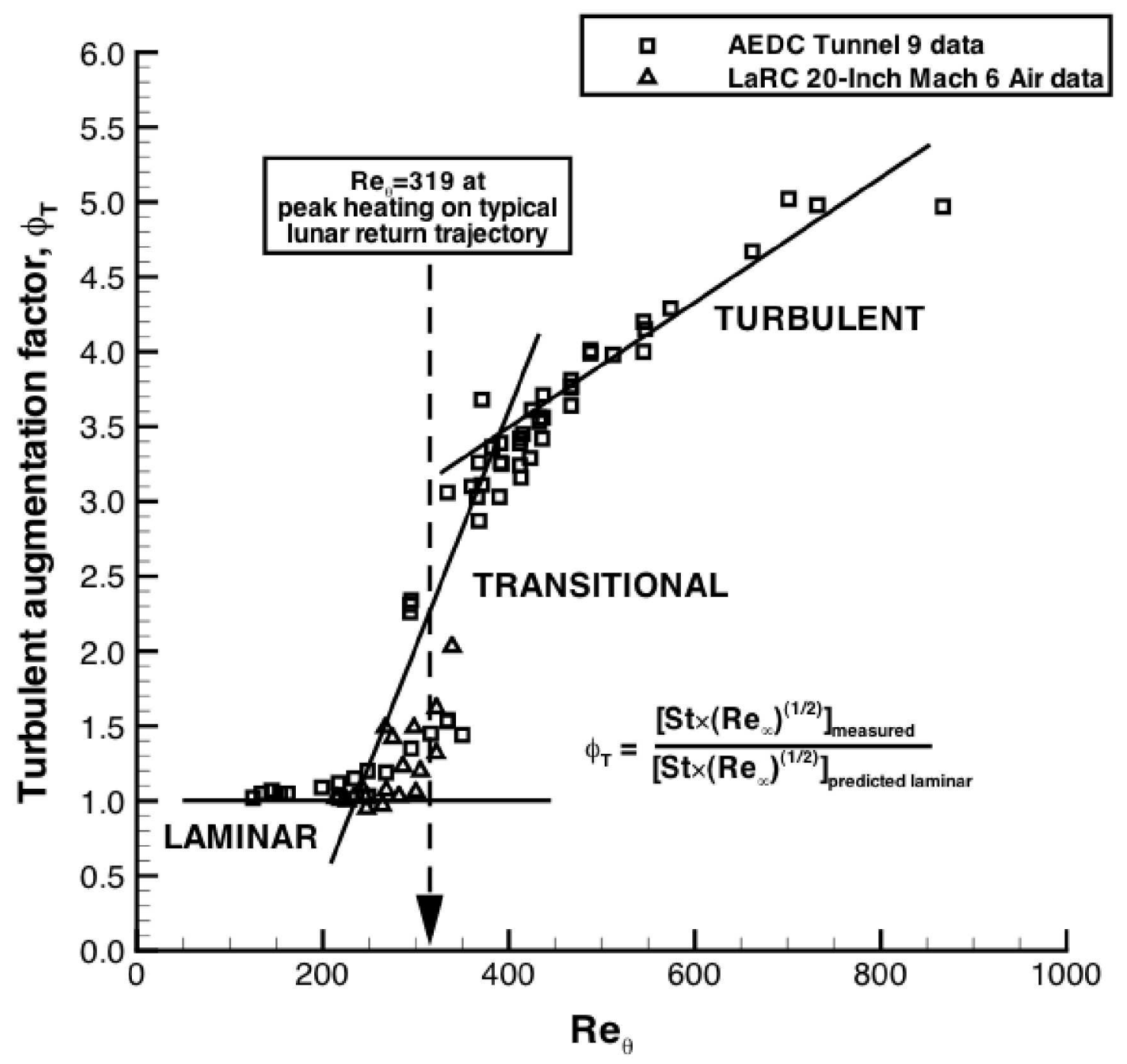

Figure 26. Leeside corner heating augmentation ratio 


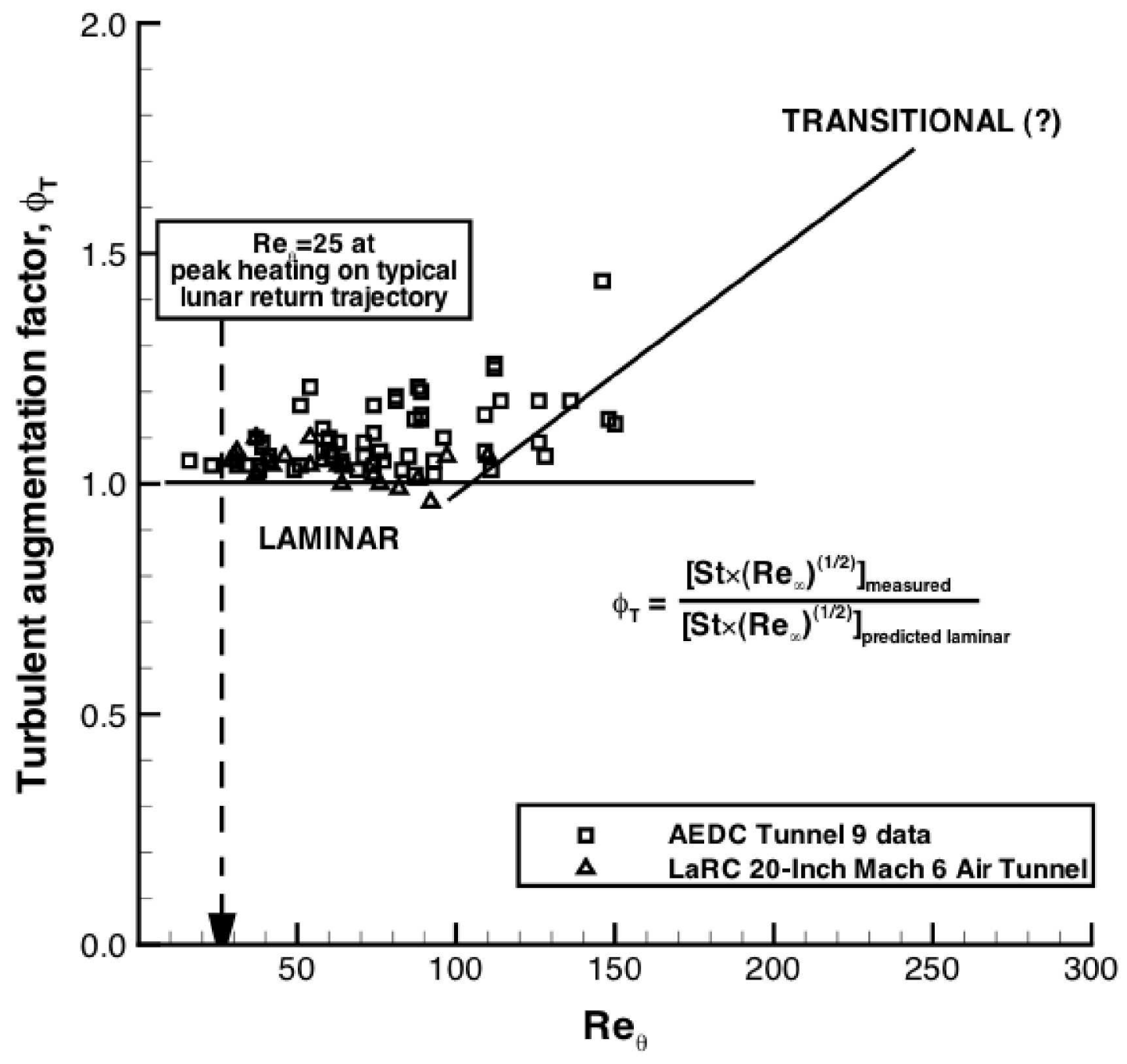

Figure 27. Windside corner heating augmentation ratio 


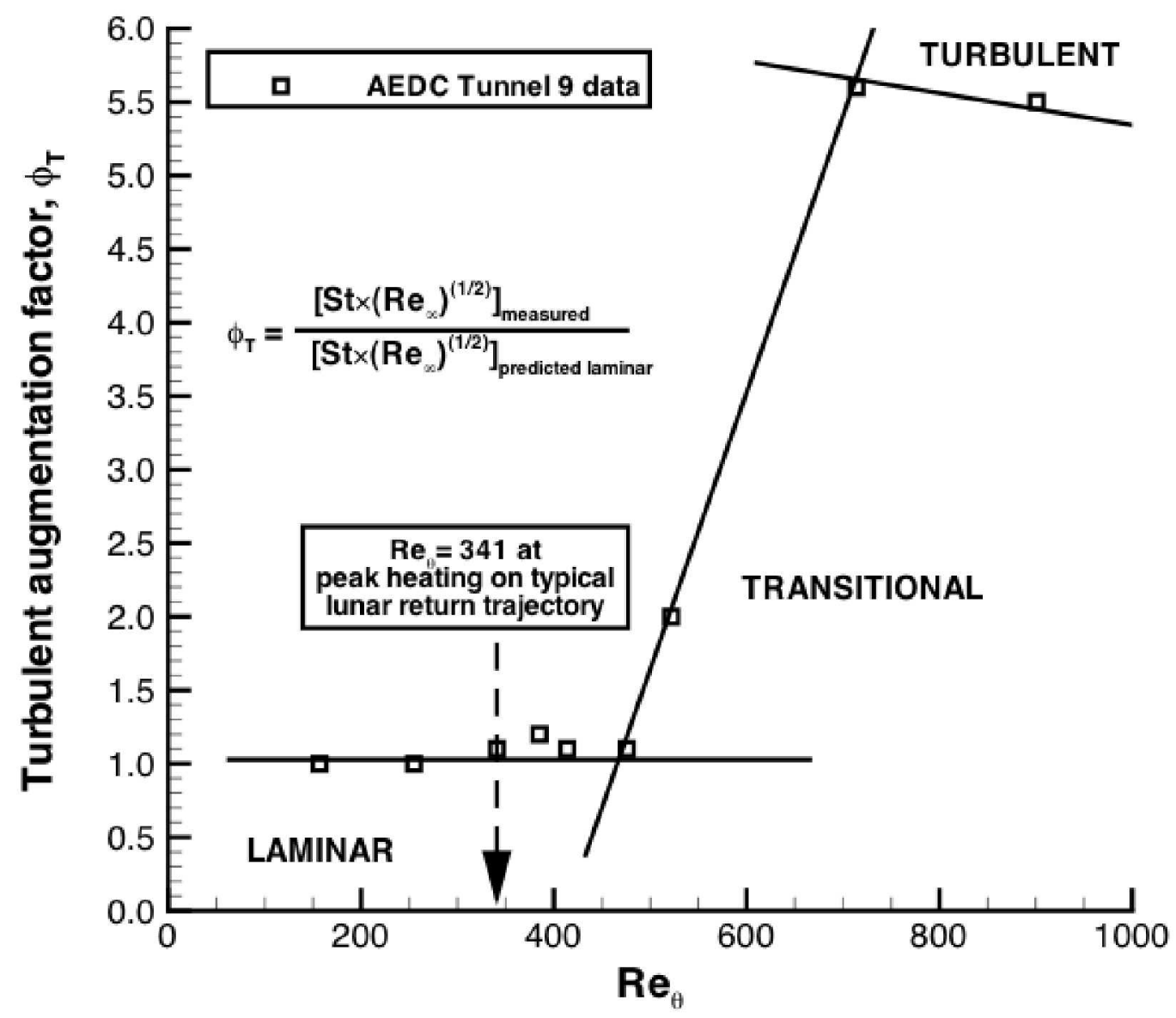

Figure 28. Aftbody augmentation ratio 
Table 1. AEDC Tunnel 9 Test Conditions

\begin{tabular}{|c|c|c|c|c|c|c|c|c|c|c|}
\hline Run & $\begin{array}{c}\alpha \\
(\mathrm{deg})\end{array}$ & $\begin{array}{c}\mathrm{Re}_{\infty} \\
(1 / \mathrm{ft})\end{array}$ & $\begin{array}{c}\mathrm{Re}_{\infty} \\
(1 / \mathrm{m})\end{array}$ & $\mathrm{M}_{\infty}$ & $\begin{array}{c}P_{\infty} \\
(\mathbf{P a})\end{array}$ & $\begin{array}{c}T_{\infty} \\
(\mathbf{K})\end{array}$ & $\begin{array}{c}\rho_{\infty} \\
\left(\mathrm{kg} / \mathrm{m}^{3}\right)\end{array}$ & $\begin{array}{c}\mathrm{U}_{\infty} \\
(\mathrm{m} / \mathrm{s})\end{array}$ & $\begin{array}{l}T_{W} \\
(K)\end{array}$ & $\begin{array}{c}\mathrm{H}_{0}-\mathrm{H}_{300 \mathrm{~K}} \\
(\mathrm{~J} / \mathrm{kg})\end{array}$ \\
\hline 3057 & 20 & $.93 E+06$ & $35 \mathrm{E}+06$ & 9.64 & $62 \mathrm{E}+02$ & 53.6 & $1.65 \mathrm{E}-02$ & 1439 & 320 & $7.79 E+05$ \\
\hline 3057 & 24 & $1.93 \mathrm{E}$ & 6.33 & 9.63 & $2.66 \mathrm{E}+02$ & 54.2 & -02 & 1446 & 320 & 7.85 \\
\hline 3057 & 28 & $1.91 E+06$ & $6.27 E+06$ & 9.63 & $2.60 \mathrm{E}+02$ & 54.5 & 1.64E-02 & 1450 & 320 & 7.96E+05 \\
\hline 3057 & 32 & $1.90 \mathrm{E}+06$ & $6.23 E+06$ & 9.62 & $2.69 E+02$ & 55.1 & 1.64 & 1457 & 320 & 8.07E+05 \\
\hline 3058 & 20 & $4.72 E+06$ & $1.55 E+07$ & 9.87 & $6.17 E+02$ & 53.1 & 3.91E-02 & 1468 & 321 & $8.21 E+05$ \\
\hline 3058 & 24 & $4.60 \mathrm{E}+06$ & $1.52 E+07$ & 9.86 & $6.23 E+02$ & 54.0 & 3.89E-02 & 1477 & 321 & $8.35 E+05$ \\
\hline 3058 & 28 & $4.58 \mathrm{E}+06$ & $1.50 \mathrm{E}+07$ & 9.85 & $6.22 E+02$ & 54.4 & 3.85 & 1483 & 321 & $8.44 E+05$ \\
\hline 3058 & 32 & $4.52 E+06$ & $1.48 \mathrm{E}+07$ & 9.85 & $6.24 E+02$ & 55.0 & 3.82E-02 & 1489 & 321 & $8.54 E+05$ \\
\hline 3060 & 20 & $9.23 E+06$ & $3.03 E+07$ & 10.11 & $1.11 E+03$ & 51.0 & 7.33E-02 & 1472 & 311 & $8.25 E+05$ \\
\hline 60 & 24 & $8.93 E+06$ & $2.93 E+07$ & 10.10 & $1.11 E+03$ & 52.2 & 7.17E-02 & 1489 & 314 & $8.51 E+05$ \\
\hline 3060 & 28 & 8.87E+06 & $2.91 E+07$ & 10.09 & $1.14 E+03$ & 53.2 & 7.20E-02 & 1501 & 316 & $8.54 E+05$ \\
\hline 3060 & 32 & $8.69 E+06$ & $2.85 E+07$ & 10.08 & $1.12 E+03$ & 53.3 & 7.07 & 1501 & 318 & $8.70 E+05$ \\
\hline 63 & 0 & $15.2 E+06$ & $4.99 E+07$ & 10.33 & $1.59 \mathrm{E}+03$ & 47.1 & -01 & 1445 & 317 & $8.25 E+05$ \\
\hline 3063 & 24 & $14.6 \mathrm{E}+06$ & $4.83 E+07$ & 10.33 & $1.60 \mathrm{E}+03$ & 48.2 & 1.10E-01 & 1468 & 321 & $8.51 E+05$ \\
\hline 3063 & 28 & $14.5 E+06$ & $4.75 E+07$ & 10.32 & $E+03$ & 49.0 & 1.10 & 1473 & 325 & $8.69 E+05$ \\
\hline 3063 & 32 & $14.3 E+06$ & $4.70 E+07$ & 10.32 & $1.61 E+03$ & 49.4 & 1.1 & 1480 & 331 & $8.34 \mathrm{E}$ \\
\hline 3061 & 20 & $20.4 \mathrm{E}+06$ & $6.70 E+07$ & 10.37 & 1.97E+03 & 44.7 & $1.4 \varepsilon$ & 1413 & 325 & $7.33 E+05$ \\
\hline 3061 & 24 & $19.4 \mathrm{E}+06$ & 6.37E+07 & 10.40 & $2.03 E+03$ & 47.3 & 1.45E-01 & 1458 & 326 & $8.01 E+05$ \\
\hline 3061 & 28 & 19.7E+06 & $6.45 \mathrm{E}+07$ & 10.42 & $2.12 \mathrm{E}+03$ & 48.4 & 1.48E-01 & 1478 & 336 & $8.31 E+05$ \\
\hline 3074 & 24 & 8.27E+06 & $2.71 E+07$ & 7.45 & $2.24 E+03$ & 71.9 & $1.05 \mathrm{E}-01$ & 1287 & 318 & $5.91 E+05$ \\
\hline 3074 & 28 & $8.16 \mathrm{E}+06$ & $2.68 \mathrm{E}+07$ & 7.45 & $2.28 \mathrm{E}+03$ & 73.3 & $1.05 \mathrm{E}-01$ & 1300 & 320 & $6.10 \mathrm{E}+05$ \\
\hline 3074 & 32 & $8.09 E+06$ & $2.65 E+07$ & 7.45 & $2.31 E+03$ & 74.6 & $1.05 E-01$ & 1312 & 322 & $6.26 \mathrm{E}+05$ \\
\hline 3075 & 24 & $16.8 E+06$ & $5.51 E+07$ & 7.57 & $5.49 E+03$ & 82.6 & 2.24E-01 & 1403 & 376 & $7.59 \mathrm{E}+05$ \\
\hline 3075 & 28 & $16.8 \mathrm{E}+06$ & $5.51 \mathrm{E}+07$ & 7.57 & $5.57 E+03$ & 83.4 & 2.25E-01 & 1410 & 386 & $7.69 E+05$ \\
\hline 3075 & 32 & $16.6 \mathrm{E}+06$ & $5.46 \mathrm{E}+07$ & 7.57 & $5.64 \mathrm{E}+03$ & 84.6 & 2.25E-01 & 1419 & 393 & $7.83 E+05$ \\
\hline 3076 & 24 & $31.4 \mathrm{E}+06$ & $1.03 E+08$ & 7.79 & $8.15 E+03$ & 72.0 & 3.82E-01 & 1347 & 369 & $6.70 \mathrm{E}+05$ \\
\hline 3076 & 28 & $30.7 E+06$ & $1.01 E+08$ & 7.80 & $8.29 E+03$ & 74.1 & 3.78E-01 & 1367 & 382 & $6.99 E+05$ \\
\hline 3076 & 32 & $30.2 E+06$ & $9.90 E+07$ & 7.80 & $8.40 E+03$ & 75.5 & 3.76E-01 & 1380 & 394 & $7.19 E+05$ \\
\hline 3073 & 28 & $47.9 E+06$ & $1.57 E+08$ & 7.96 & $1.18 E+04$ & 70.6 & 5.66E-01 & 1360 & 330 & $6.87 E+05$ \\
\hline
\end{tabular}

Table 2. LaRC 20-Inch Mach 6 Air Tunnel Test Conditions

\begin{tabular}{cccccccccc}
\hline $\begin{array}{c}\alpha \\
(\mathrm{deg})\end{array}$ & $\begin{array}{c}\mathrm{Re}_{\infty} \\
(1 / \mathrm{ft})\end{array}$ & $\begin{array}{c}\mathrm{Re}_{\infty} \\
(1 / \mathrm{m})\end{array}$ & $\mathrm{M}_{\infty}$ & $\begin{array}{c}\mathrm{P}_{\infty} \\
(\mathrm{Pa})\end{array}$ & $\begin{array}{c}\mathrm{T}_{\infty} \\
(\mathrm{K})\end{array}$ & $\begin{array}{c}\rho_{\infty} \\
\left(\mathrm{kg} / \mathrm{m}^{3}\right)\end{array}$ & $\begin{array}{c}\mathrm{U}_{\infty} \\
(\mathrm{m} / \mathrm{s})\end{array}$ & $\begin{array}{c}\mathrm{T}_{\mathrm{w}} \\
(\mathrm{K})\end{array}$ & $\begin{array}{c}\mathrm{H}_{0}-\mathrm{H}_{300 K} \\
(\mathrm{~J} / \mathrm{kg})\end{array}$ \\
\hline $20-32$ & $3.02 \mathrm{E}+06$ & $9.91 \mathrm{E}+06$ & 6.0 & 840.8 & 62.6 & $4.68 \mathrm{E}-02$ & 950.6 & 300 & $2.14 \mathrm{E}+05$ \\
$20-32$ & $3.91 \mathrm{E}+06$ & $1.28 \mathrm{E}+07$ & 6.0 & 1109.0 & 63.4 & $6.10 \mathrm{E}-02$ & 956.2 & 300 & $2.20 \mathrm{E}+05$ \\
$20-32$ & $5.09 \mathrm{E}+06$ & $1.67 \mathrm{E}+07$ & 6.0 & 1446.0 & 63.5 & $7.96 \mathrm{E}-02$ & 956.0 & 300 & $2.20 \mathrm{E}+05$ \\
$20-32$ & $5.89 \mathrm{E}+06$ & $1.93 \mathrm{E}+07$ & 6.0 & 1677.0 & 63.4 & $9.22 \mathrm{E}-02$ & 955.9 & 300 & $2.20 \mathrm{E}+05$ \\
$20-32$ & $7.37 \mathrm{E}+06$ & $2.42 \mathrm{E}+07$ & 6.0 & 2131.9 & 64.2 & $1.16 \mathrm{E}-01$ & 960.4 & 300 & $2.25 \mathrm{E}+05$ \\
\hline
\end{tabular}

39

American Institute of Aeronautics and Astronautics 